\title{
Resolved Shear Stress Intensity Coefficient and Fatigue Crack Growth in Large Crystals
}

Qi Chen and Hao-wen Liu

Syracuse University

Syracuse, New York



June 1988

Prepared for

Lewis Research Center

Under Grant NAG3-348

\section{Nusn \\ National Aeronautics and \\ Space Administration}



RESOLVED SHEAR STRESS INTENSITY COEEFICIENT

AND FATIGUE CRACK GROWTH IN LARGE CRYSTALS

\section{INTRODUCTION}

Fatigue crack propagation by cyclic plastic deformation on a slip plane early in the fatigue life is known as Stage I crack growth [1]. In Stage I crack growth in a polycrystal, the crack plane is a slip plane and it also coincides with the plane of the maximum shear stress.

Neumann [2,3] and Vehoff and Neumann [4] have found that when a tensile stress was applied to a single crystal, a fatigue crack grew by the shear decohesion on two intersecting conjugate slip planes inclined to the tensile axis. The local small crack increments all took place on these two conjugate slip planes, while the macroscopic crack plane was perpendicular to the tensile axis.

Even during stage II crack growth in a polycrystal, it has been generally agreed that a fatigue crack grows by the shear decohesion mechanism. Based on the shear decohesion process, Kuo and Liu [5], Yang and Liu [6], and Liu [7] have proposed an unzipping fatigue crack growth model. Their calculated fatigue crack growth rate agrees very well with the measured stage II growth rate and striation spacing.

Extensive studies of fatigue crack growth have been conducted on Ni-base single crystals $[8,9,10,11,12]$, and other aluminum-base single crystal alloys $[13,14]$ as well as pure aluminum single crystals 
$[15,16]$. All of these studies have shown that fatigue crack growth is highly sensitive to the orientation of the crystal, and that the crack plane is crystallographic and follows a single slip plane or a combination of several slip planes.

Since shear decohesion on a slip plane is caused by dislocation motion, the resolved shear stress acting on the active slip plane ahead of a crack tip must be resposible for the propagation of the fatigue crack as suggested by many researchers $[10,13,15]$. Several models have been proposed as the mechanisms of Stage I shear crack growth $[9,15,17,18]$

Recent work by Chan et al. [12] on fatigue crack growth in MAR-M200 single crystals revealed that fatigue crack growth is mainly crystallographic cracking on $\{111\}$ planes. At room temperature, fatigue crack growth rates were found to be orientation dependent. Based on the elastic energy release rate associated with the mixed mode fracture, the effective stress intensity factor range $\Delta \mathrm{K}_{\mathrm{eff}}$ was used to correlate crack growth, which incorporates $K_{I}, K_{I I}$, and $K_{I I I}$ for an anisotropic crystal.

For fatigue crack growth in a single crystal or in a large grain, the anisotropy of plasticity must be taken into consideration. Hence, the stress intensity factors alone may not be sufficient for correlating with crack growth rate. In addition, the fracture plane of Stage I growth is crystallographic and often inclined not only to the loading axis but also to the specimen broad surface. Therefore, the mode of cracking is mixed, consisting of Mode I, II, and III components. A successful study must take both of these factors into account. 
In our previous study of fatigue crack growth in coarse grain Al 7029 aluminum alloy [19], the fracture surfaces were planar areas parallel to either $\{111\}$ or $\{100\}$ planes. The $\{111\}$ crack surfaces were planar and shiny. They were formed primarily by shear decohsion on a single-slip-plane. The $\{100\}$ crack surfaces show "pine tree" morphology presumably formed by shear decohesions on two sets of intersecting slip planes.

In this study, fatigue crack growth tests were carried out on large grain Al 7029 aluminum alloy. The crack path is usually very irregular. The finite element method is used to calculate the stress field near the tip of a zigzag crack. The resolved shear stresses on all twelve slip systems are computed, and the resolved shear stress intensity coefficient, RSSIC, is then defined. RSSIC is used to analyze the irregular crack path, and it is used to correlate with the rate of single-slip-plane shear crack growth.

\section{EXPERIMENTAL PROCEDURES}

The material used in this study was Al 7029 aluminum alloy received as extruded 1/4" thick plates. The chemical composition in weight percent was $1.68-\mathrm{Mg}, 4.68-\mathrm{zn}, 0.78-\mathrm{Fe}$, and $0.058-\mathrm{Si}$. The alloy was of high "purity" with very little impurities other than the specified chemical composition to promote grain growth.

The plate was annealed at $540^{\circ} \mathrm{C}$ for about 50 hours followed by water quenching. The average grain size obtained after heat treatment was about $1 \mathrm{~cm}$ in diameter, with some exceptionally large grains 
reaching $2.5 \mathrm{~cm}$ in diameter.

Compact tension specimens were fabricated from the heat treated plates. The dimensions and a photograph of the specimen are shown in Figures 1 and 2. The outline of the grain boundaries can be clearly seen.

Prior to the fatigue test, all specimens were mechanically polished and etched to reveal the grain boundaries. Fatigue crack growth tests were conducted under load-controlled conditions. The frequency was either 10 or $20 \mathrm{~Hz}$ at $\mathrm{R}=0.1$. The crack growth was monitored with a travelling microscope with a magnification of $100 x$. The orientations of the crystals at the crack tips, as well as the $f$ zacture surfaces, were determined with $\mathrm{X}$-ray Laue method.

\section{RESULTS AND DISCUSSIONS}

\section{A. Orientations of the crack surfaces}

Figure $3 a .1$ is a photograph of the broken specimen, R1. Part of the fracture surface lies on a slip plane and part does not. The fracture area $A$ is a non-slip-plane fracture surface, while area $B$ is parallel to a $\{111\}$ slip plane. C designates the final area of fracture. The narrow strip bounded by dashed lines in the top sketch of Figure 3a.ii is the fracture surface. Fracture areas A, B, and C are also marked within the strip. Both of the side surfaces of the specimen are unfolded upward; the grain structure of the specimen is also shown in the figure.

The lower sketch of Figure $3 a . i i$ is the profile of the fracture 
surface viewed from the broad side of the speciman on which the crack growth was monitored. Since area $A$ is nearly perpendicular to the side face, area $A$ becomes a line in the lower sketch. On the other hand, areas $B$ and $C$ are inclined toward the viewer, so both areas can be seen In the sketch. Similar sketches for other specimens are presented in Figures $3 b$ through $3 e$.

The macroscopic crack surfaces can be classified into two categorles: slip-plane crack surface and non-slip-plane crack surface. A crack surface often changes its orientation from one grain to the next, and a crack may switch from slip-plane cracking to non-slip-plane cracking and vice versa, forming a zigzag crack path. The orientations of these crack planes were determined by the $\mathrm{x}$-ray Laue photographs taken either from the crack surface or from the side face of the specimen. Slip-plane cracking can be easily identified from their bright appearance and the straight and sharp intersections with specimen sidefaces.

slip-plane cracking is caused by shear decohesion on a single slip plane, while non-slip-plane cracking is a result of alternate shear decohesion on two or more different slip planes. Shear decohesion is due to dislocation motion, which is controlled by the forces on the dislocations at a crack tip. The force on a dislocation is directly related to the resolved shear stress on the slip plane. Therefore, the rate of shear decohesion must be related to the resolved shear stress "intensity" at a crack tip.

The crack tip stress field will be calculated by the finite element method for the zigzag crack path of each specimen. With the orientation of the crystal at a crack tip determined by the Laue $x$-ray 
pattern, the resolved shear stress field on each of the twelve slip systems at a crack tip is computed and its intensity evaluated.

The active shear decohesion plane or planes must be the slip plane(s) with a high resolved shear stress intensity. If the resolved shear stress intensity on a plane is much higher than all the rest, the plane must be the primary plane of shear decohesion and the slip plane becomes the crack plane. On the other hand, if the resolved shear stresses on two slip systems are comparable, shear decohesion will take place on both of these two slip planes, and the macro crack plane will not follow a single slip plane. The orientations of the crack surfaces will be analyzed with the computed resolved shear stress intensities. If a crack surface is a slip plane, it is logical that the crack growth rate on the single slip plane will correlate with its resolved shear stress intensity.

B. Finite Element Modelling of the Crack Tip Resolved Shear Stress The sketches in Figures $3 a$ to $3 e$ indicate that crack paths are very irregular and zigzag. The elastic crack tip stresses of such zigzag crack are calculated by FEM. A two-dimensional plane model of a through crack is used to simulate the actual crack. Both Mode I and Mode II crack tip fields are calculated.

The real crack surface is three-dimensional and often inclined to the broad surface of a specimen. The inclination of the crack surface induces Mode III crack tip field. The Mode II crack tip field is obtained by an approximation.

Once the Mode I, II, and III crack tip fields are obtained, the resolved shear stresses on various slip systems of the crystal at the 
crack tip can be calculated. The resolved shear stress field of a slip system is defined by its intensity coefficient.

Figure 4 shows the sketch of a crack in a compact tension specimen for the FEM simulation. Although a real crack may be zigzag, the crack in the simulation consists of a machined notch and an inclined crack. The inclined crack is a two-dimensional through crack and the crack surface is perpendicular to the broad specimen surface. The inclination angle $\alpha$ is defined as shown in the figure.

The local coordinate with the origin at the crack tip is shown in the figure. The $x^{\prime}$-axis is defined as the line along the inclined crack; and $y^{\prime}$-axis, perpendicular to the crack line. The $r$ and $\theta$ are local polar coordinates, defined in the conventional manner.

Flgure 5 shows a typical finite element mesh for a compact tension specimen. The ABAQUS FEM program was used. The crack tip elements consist of eight layers. The plane eight-noded quadrilateral quadratic isoparametric element was used. The crack tip triangular elements were formed by collapsing one side of the quadrilateral element. The mid-node of a crack tip element was moved to the quarter point to take account of the elastic singularity of the crack tip field.

To insure proper finite element modelling, the crack tip stress field of the conventional compact tension specimen with a straight crack was calculated. The calculated stresses at $\theta=0^{\circ}$ were plotted as a function of $r$, the distance from the crack tip, and the results were compared with known solution. As shown in Figure 6, the finite element calculation yields very satisfactory results.

In the case of an inclined crack, the crack tip stresses are 
given by: (referring to Figure 4 for the definition of the local coordinates)

$$
\sigma_{i} j^{\prime}=\frac{K_{I}}{\sqrt{2 \pi r}} \tilde{\sigma}_{i \prime j^{\prime}, I}(\theta)+\frac{K_{I I}}{\sqrt{2 \pi r}} \tilde{\sigma}_{i \prime j^{\prime}, I I}(\theta)
$$

Along the crack line, i.e. $\theta=0^{\circ}$, or along the $x^{\prime}$-axis,

$$
\begin{aligned}
& \sigma_{x^{\prime} x^{\prime}}=\sigma_{y^{\prime} y^{\prime}}=\frac{K_{I}}{\sqrt{2 \pi r}} \\
& \tau_{x^{\prime} y^{\prime}}=\frac{K_{I I}}{\sqrt{2 \pi r}}
\end{aligned}
$$

Thus, the stress intensity factors, $K_{I}$ and $K_{I I}$, can be evaluated from

$$
\begin{aligned}
& K_{I}=\sigma_{Y} Y^{\prime} \sqrt{2 \pi r} \\
& K_{I I}=\tau_{X^{\prime} Y^{\prime}} \sqrt{2 \pi r}
\end{aligned}
$$

where $\sigma_{y^{\prime}} y^{\prime}$ and $\tau_{x} y^{\prime}$ are the computed local stresses along the crack line, which are obtained by transforming the calculated stress components of a inclined crack into the $x^{\prime-a x e s .}$

Figure 7 shows an example of the $\log -\log$ plot of $\sigma_{y^{\prime}} y^{\prime}$ and $\tau_{x} y^{\prime}$ v.s the distance from the crack tip, $r$. Figure 8 is a plot of $K_{I}$ and $K_{I I}$ computed from Equations 4 and 5 as functions of $\log r$. Notice that $K_{I}$ and $K_{I I}$ are nearly constant at the distance very close to the crack tip. These asymptotic values of $K_{I}$ and $K_{I I}$ are, therefore, taken as the norminal $K_{I}$ and $K_{I I}$ for the crack geometry.

The crack tip field for a through crack with a crack surface 
inclined to the broad surface of a specimen is characterized by $K_{I}, K_{I I}$ and $K_{\text {III }}$. A two-dimensional FEM calculation can only give $K_{I}$ and $K_{I I}$. As a consequence, a procedure is adopted to obtain the approximate values of $K_{I}, K_{I I}$, and $K_{I I I}$ for the inclined crack. The detailed derivations are given in the Appendix.

The approximation for the inclined crack was proposed by Pook [20] and Chan and Cruse [21]. The calculated Mode I and Mode II crack tip fields are projected onto the inclined crack surface. The equations for the K's in the case of three-dimensional inclined crack are given by

$$
\begin{aligned}
& \mathrm{K}_{I}^{\prime}=\mathrm{K}_{\mathrm{I}} \cos ^{2} \beta \\
& \mathrm{K}_{I I}^{\prime}=\mathrm{K}_{\mathrm{II}} \cos \beta \\
& \mathrm{K}_{\text {III }}^{\prime}=\mathrm{K}_{\mathrm{I}} \cos \beta \sin \beta
\end{aligned}
$$

where $K_{1}$ and $K_{I I}$ are stress intensity factors obtained from the twodimensional finite element calculation; $\beta$ is the angle of the inclination of the crack surface, defined as the angle between the normal of the crack plane and the $y^{\prime}$-axis.

For a three-dimension inclined crack geometry, the crack tip stress components are given by



$$
\begin{aligned}
& r \text { and } \theta \text { are the local polar coordinates at the crack tip as shown in }
\end{aligned}
$$


Figure 4 .

In an earlier study by Duquette et al. [10] on Stage I fatigue cracking in a Nickel-base superalloy single crystal, the glide forces on a dislocation lying in all possible slip planes were calculated. The calculation showed that crack growth is directly related to slip activities on slip systems having the highest resolved shear stresses.

Similar procedures were followed by Nageswararao et al. [13] on Stage I fatigue propagation study in an Al-Zn-Mg alloy. Relative shear stress values on various slip systems at a given distance from the crack tip were computed. Fatigue cracks propagated preferentially in the slip system that experiences the maximum resolved shear stress.

The resolved shear stress is given by [22]

$$
\tau_{\text {Rs }}=\frac{1}{b} b_{i} \sigma_{i j} \mathbf{n}_{j}
$$

where $b_{i}$ and $b$ are the Burgers vector and its magnitude; $n_{j}$ the unit normal vector of the slip plane; and $\sigma_{i j}$ the crack tip stress tensor fleld. Substituting Equation 9 into Equation 10, the resolved shear stress is



As defined in the Appendix, $x_{i}$ " are the principal axes of the crystal. $C_{i}{ }^{\prime}$ ' are the direction cosines between $x_{i}$ " and $x_{j}$ ' $b_{i}$ " is the Burgers vector; $n_{j n}$ the unit normal vector of the active slip plane referring to the $x_{i} "$ coordinate system. The matrix containing $K^{\prime} s$ and $f(\theta)$ is the stress matrix, whose component is defined by Equation 9 . 
Equation 10 indicates that $\tau_{\mathrm{R} s \mathrm{~s}}$ preserves the $1 / \mathbb{V}_{\mathrm{r}}$ singularity, and the intensity of $\tau_{\mathrm{RSS}}$ is dependent on the crystal orientation relative to the crack surface. For a given crystal orientation and crack geometry, the angle $\theta$ is equal to $\theta_{3}$, the angle between the intersection of the slip plane with the broad surface of the specimen and the $x^{\prime}$-axis as defined in Figure 4 . $\tau_{\mathrm{R} S \mathrm{~s}}$ is a function of $r, \theta_{3}$ and the values of $\mathrm{K}$ 's.

The intensity of $\tau_{R S S}$ is linearly proportional to the quantity RSSIC, which is defined as following

$$
\text { RSSIC }=\left[b_{1} n\right]\left[C_{1} \|_{1}\right]\left[K_{I}^{\prime}, K_{I}^{\prime}, K_{I I}, f\left(\theta_{s}\right)\right]\left[C_{1} n_{1}\right]^{T}\left[n_{j} n\right]
$$

We call the quantity the resolved shear stress intensity coefficient (RSSIC). For a given slip system, $\tau_{\mathrm{RSS}}$ is

$$
\tau_{\mathrm{RSS}}=\frac{\mathrm{RSSIC}}{\sqrt{2 \pi r}}
$$

The intensity of $\tau_{\mathrm{RSS}}$ of this slip plane depends on the RSSIC value, which is analogous to stress intensity factor $K$. However, $K$ is applicable to any angle $\theta$, while RSSIC is applicable only to a specific siip plane. For different slip systems the values of RSSIC's are different. RSSIC can be used to characterize the resolved shear stress of a given slip system and the forces on the dislocations of the slip system. Therefore, it can be used to characterize the slip behaviors of the slip system and the shear decohesion process at a crack tip.

Two advantages in using RSSIC are: (1) the dependence of $\tau_{R S S}$ on $r$ is eliminated; (2) the angle $\theta_{S}$ has a definite physical meaning, which 
is directly related to the orientation of the slip plane.

In the following section, the detailed analyses are presented for the relationship between the resolved shear stress intensity coefficients and the fracture planes of the tested specimens.

\section{RSSIC and the Active Slip Plane}

It is well established that ductile fatigue crack growth is caused by shear decohesion $[2,3,4,23,24,25]$. Shear decohesion is caused by dislocation motion. Therefore, it is expected that the orientation of the crack plane must be related to the active slip plane(s). A detailed quantitative study on the RSSIC and its relation to the active slip plane(s) will be very useful to advance the study of the shear decohesion process.

Four speicmens were tested and analyzed. Crack surfaces of two specimens follow the $\{111\}$ slip planes, and another two specimens have non-slip-plane crack surfaces.

1. Specimens with slip-plane fracture surface Specimens R2 and R3 are good examples of slip-plane fracture surface. The sketches of the crack surfaces are shown in Figures $3 b$ and 3c. Figure 9 shows a photograph of the fractured specimens R2 and R3. The slip-plane fracture surfaces of these two specimens are very shiny, smooth, and reflective to naked eyes.

The orientations of the crystals at the crack tips were determined by $x$-ray Laue method. They are very close to each other. A stereographic projection of the crystal is presented in Figure 10. The loading axis (LA) and the crack propagation direction (CPD) are marked 
in the figure. The macroscopic crack plane of each of these two spcimens followed a single $\{111\}$ plane.

For Specimen R3, the crack was initiated at the center of the machined Chevron notch because of the high tensile stresses there. After the crack initiation, it was observed that on one side of the specimen surface, the crack propagated vertically downward at first. Then the crack turned forward. On the other side of the specimen, however, the crack propagated straight forward, but slightly off the specimen center line. After the initial transition stage, the crack front shifted to the (111) slip plane, which is inclined to the thickness direction of the specimen. From thereon, the crack continued to propagate on this plane until final fracture. A similar behavior was observed on Specimen R2.

The stress state in the initial stage is too complicated to investigate. The analysis is made mainly for the major portion of the crack, i.e. along the (111) crack surface.

First, we have to calculate the RSSIC of each slip system and to locate the active slip plane(s). Both specimens have the same crack angle (1.e. $\alpha=3^{\circ}$ ) and same crystal orientation with respect to the local coordinates at a crack tip. The relative orientation is given by the matrix of the direction cosines $\left[C_{i " j}\right]$. With $\alpha,\left[C_{i " j}\right]$ and the crack tip field, i.e. $K_{I}^{\prime}, K_{I}^{\prime}$, and $K_{I I I}^{\prime}$ known, the resolved shear stress intensity coefficients, RSSIC, for all 12 slip systems are calculated with Equation 12 . The results of the calculation are tabulated in the first column of Table 1 for the projected crack length of $\mathrm{a}^{\prime} / \mathrm{w}=0.423$, where $\mathrm{a}^{\prime}=\ell+a \cos \alpha$, as indicated in Figure 4.

The solid line segment at the left hand side of the sketch at the 
bottom of the first column in Table 1 is the notch. The next solid line segment to the right is the crack, which follows (111) plane with an inclination angle $\alpha=3^{\circ}$. The dashed line segments indicate the orientations of other $\{111\}$ planes.

From the table, one can see that the value of RSSIC on (111) [10̄]] slip system (underlined) is much higher than all others. Therefore, this must be the dominant crack tip slip system. The orientation of (111) sl1p plane coincides with that of the crack surface.

We also explore the possibility that the carck may turn to one of the other three slip planes. Additional calculations with $(11 \overline{1}),(\overline{1} 11)$ and $(1 \overline{1} 1)$ crack increments are made.

The values of RSSIC for the crack increment along the (1II) slip plane are listed in the second column. The highest value takes place on the (111) $[01 \overline{1}]$ slip system. Therefore, once a crack follows the


(i11) plane.

The calculations for the crack increment along the (ī11)-plane are

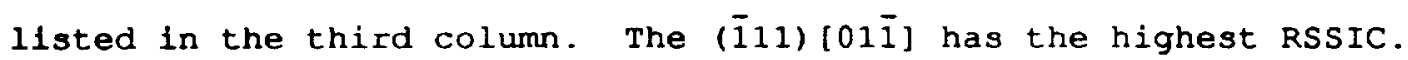
However, the value is still much lower than that of the (111)[10 $\overline{1}]$ slip system. The RSSIC controls the dislocation motion. Therefore, the shear decohesion process takes place on the (111)-plane as observed. If localized softening takes place in the active slip band, a further concentration of the slip motion in this band will be promoted as suggested by Nageswararao et al. [8].

Figure 11 is an optical photograph of the fracture surface. Many parallel slip markings across the specimen thickness are clearly visible. The markings spread over the entire fracture surface until 
the final area of failure. From the $x$-ray Laue photograph, these slip markings were identified to be parallel to the $[10 \overline{1}]$ direction, which is the intersection between the (111) crack plane and the (1 $\overline{1} 1$ ) slip plane. It is interesting to observe that with the (111) crack plane

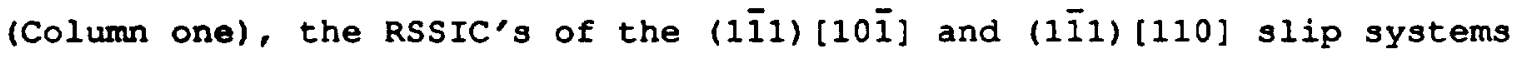
are also very high. These markings indicate that one or both of these two slip systems were also active. However, the shear decohesion on this slip plane did not make any significant contribution to the crack growth rate.

The values of RSSIC for the crack increment along the (IIII)-plane, the fourth column, are much lower than those for the crack increments

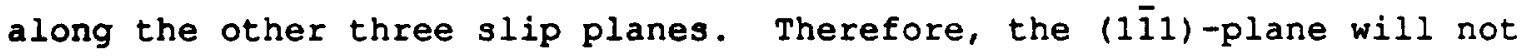
participate actively in the shear decohesion process.

Since Specimen R2 has the same crystal orientation and fracture surface as R3, the above calculations, analyses and conclusions are equally applicable.

For a single active slip plane, the maximum resolved shear stress provides the primary driving force for dislocation motion, the shear decohesion process, and, thereby, the crack growth process. The correlation of the crack growth rate on such plane with the calculated range of RSSIC, $\triangle R S S I C$, will be shown in a later section.

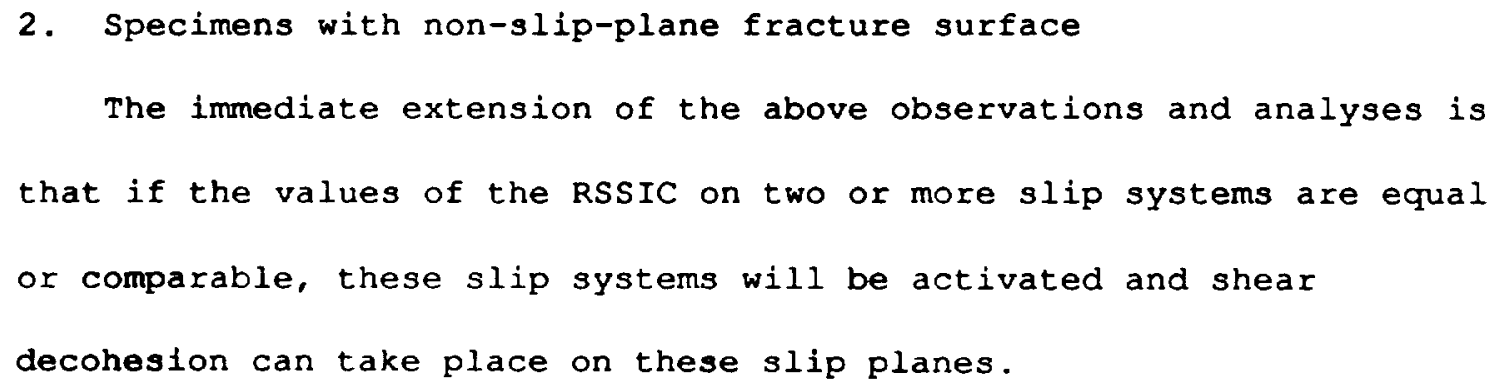


The model for ductile fracture and ductile fatigue crack growth proposed by Orowan [26], Neumann [3], McEvily [15], Laird [23], Pelloux [24], and Tomkins [25] involves the alternate shear decohesion process on two intersecting conjugate slip planes passing through the crack tip.

When the alternate shear decohesion process takes place on two
Intersecting conjugate $\{111\}$ slip planes in a FCC crystal, the
macroscopic fracture plane will coincide with a $\{100\}$ plane as observed
by Neumann [3] in copper single crystals. The copper crystal was oriented so that the notch plane was parallel to the $\{100\}$ plane, and two $\{111\}$ slip planes were symetrical to the notch plane, i.e. one above and the other below the notch plane. See Figure 12 . The shear decohesion process alternated between these two $\{111\}$ slip planes. While the microscopic crack plane always follows the $\{111\}$ planes, the resultant macroscopic fracture surface is parallel to the $\{100\}$ plane, 1.e. a non-slip-plane fracture surface for the copper crystal.

The distinction between the slip-plane and the non-slip-plane fracture surfaces can be readily seen from the morphologies of the fracture surfaces of specimens R4 and R5 in Figures 13 and 14, respectively. The common features of the fracture surfaces of these two specimens are very rough surface, divergent river lines originating from the notch tip, and the lack of macroscopically well-defined slip markings .

The stereographic projections of these two cystals are shown in Figures 15 and 16 . The macroscopic crack planes were also determined by the Laue $x$-ray method. These planes are very close to $\{100\}$-planes. The stereographic projection of the crack plane of Specimen R5 is shown 
in Eigure 17. Notice that the center of the projection is very close to the $\{100\}$ pole. Both crack planes were nearly perpendicular to the specimen broad surfaces, i.e. $\beta \cong 0^{\circ}$. The angles of inclination, $\alpha$, are 10 degrees and 33 degrees for R4 and R5, respectively.

For specimen R4, four sets of calculations are made. The first set is for the basic inclined crack at $\alpha=10^{\circ}$. Three additional sets of calculations are made for the crack configurations shown at the bottom of each column. Each crack configuration has a segment as the notch and a segment as the inclined crack at $\alpha=10^{\circ}$ followed by additional segment (s) as shown in the sketches.

The first column is the calculation of the crack tip stress field for the projected crack length of $\mathrm{a}^{\prime} / \mathrm{w}=0.374$. The initial solid line segment at the left hand side of the sketch at the bottom of the first column in Table 2 is the notch. The next solid line segment to the right is the crack, which has an inclination angle $\alpha=10^{\circ}$.

After the crack tip stress field is calculated, the values of RSSIC of the 12 slip systems are then computed. The results are listed in the first column of Table 2. In the table, the higher values of RSSIC are underlined.

The slip systems $(1 \overline{1} 1)[10 \overline{1}]$ and $(1 \overline{1})[1 \overline{1} 0]$ experience much higher

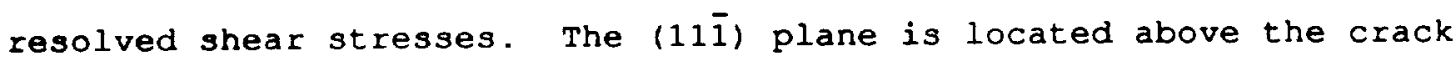
plane; while the $(1 \overline{1} 1)$ is below the crack plane. This suggests that a crack may grow alternately on these two slip planes and the resultant macroscopic fracture plane is somewhere in between these two planes. The actual crack plane nearly bisects the angle between these two active slip planes.

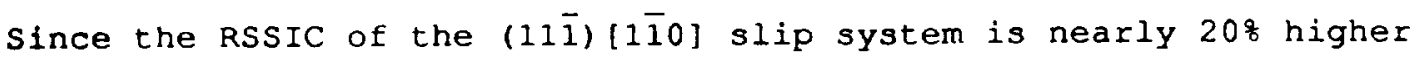


than that of $(1 \overline{1} 1)[10 \overline{1}]$ slip system, it cannot be ruled out that the

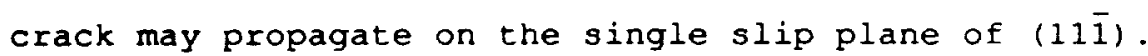

Assume that the crack will grow on the (11̄i) slip plane. A finite element calculation is made for the new crack geometry. After the initial crack segment at $\alpha=10^{\circ}$, a small crack increment along the

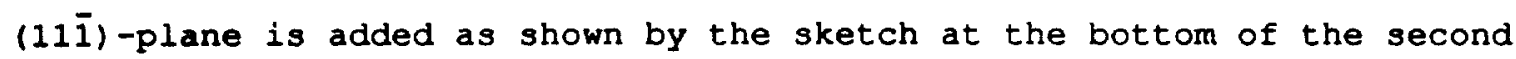
column.

The second colum in Table 2 shows the calculated RSSIC of all slip systems based on this new crack geometry. Ralatively high RSSIC values are retained on these two slip systems. This implies that there is no substantial difference in the driving forces for dislocation motion

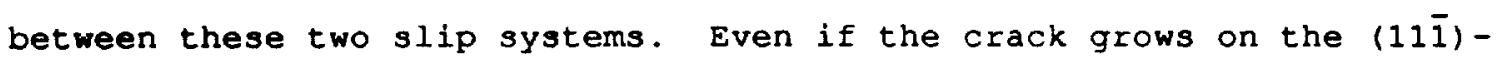
plane, the crack may switch back to the (1ī1)-plane. Therefore, the

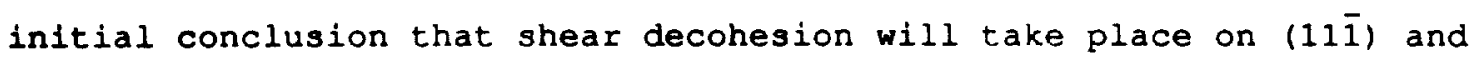
(1īi)-planes is still valid.

Additional calculation is made by assuming that the crack further


segment along the (1iil)-plane is added as shown by the sketch at the bottom of the third column. The calculated RSSIC value is listed in the third column. Again, the RSSIC values on these two slip planes remain higher than those of the others.

It should be pointed out that the sequence in which the crack switches between ( $1 \overline{1} 1$ ) and (11i) planes does not affect our conclusion. This is depicted by the calculations by assuming that the crack will switch from the inclined crack at $\alpha=10^{\circ}$ onto the (1î1)-plane directly. The result is listed in the fourth column of the table. These calculations demonstrate that no matter on which slip plane 


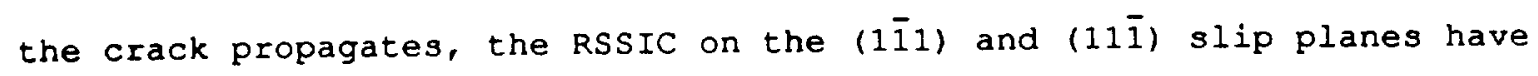
the highest values. The (11i) plane is above the crack plane and the (1ii) is below the crack plane. Therefore, the shear decohesion processs will alternate between two planes, and results in a non-slipplane fracture surface very close to the (100)-plane.

As determined from the stereographic projection of the crystal, the


of the specimen by -54 degrees $\left(\theta_{s}=-54^{\circ}\right)$ and 59 degrees $\left(\theta_{S}=59^{\circ}\right)$, respectively. The crack plane deviates from the bisectional plane of these two slip planes by $2.5^{\circ}$, i.e. $\frac{1}{2}\left(59^{\circ}-54^{\circ}\right)$.

For Specimen R5, the inclined crack angle, $\alpha$, is $33^{\circ}$. Four sets of calculations were made for the crack geometries shown by the sketches in Table 3. The calculations were made for the initial projected crack length of $\mathrm{a}^{\prime} / \mathrm{w}=0.32$.

First column of the table shows the values of RSSIC for the crack with an inclined angle of $33^{\circ}$. The two highest values are RSSIC $=2.01$

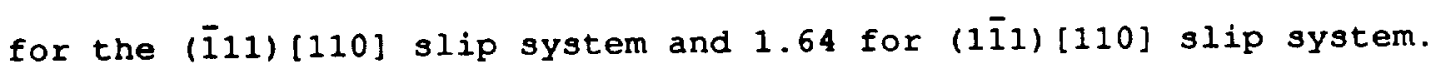
Additional calculations were made for the crack increments along the

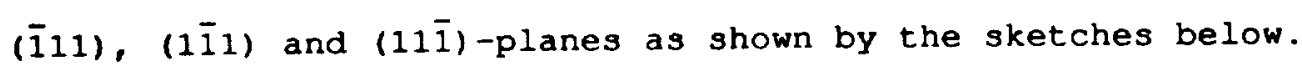

The higher values of RSSIC are underlined. The results indicate that if a crack propagates along (111)-plane, it will continue to grow on this plane. Therefore, it becomes and slip-plane cracking. However, it also indicates that once a crack switches to either (1īi)

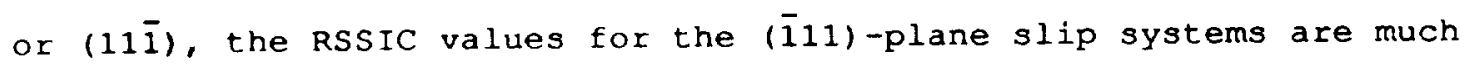

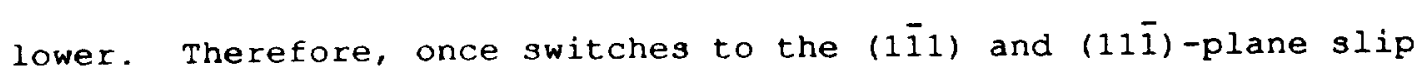
systems, the crack will not be able to go back to the (111)-plane. There are a number of dislocation barriers in a crystal to cause cross 
slip from (i11) to $(1 \overline{1} 1)$ or $(1 \overline{1})$. (1iil) is above the crack plane and (11i) is below. The crack will grow by the shear decohesion process alternately between $(1 \overline{1} 1)$ and (11i)-planes. The crack plane bisects these two slip planes and it is close to the $(010)$ plane.

D. Growth Rate of Single Slip-plane Shear Crack

The discussion thus far have clearly indicated that the resolved shear stress coefficient is capable of characterizing slip behaviors on specimens with either slip-plane fracture surface or non-slip-plane fracture surface. Since shear crack growth is a shear induced slip process, the parameter directly related to localized shear stress acting on specific slip plane, RSSIC, is a "natural" candidate as the controlling factor. In terms of dislocation mechanics, the glide force is the resolved shear stress acting on the slip plane in a slip direction, which provides a driving force for dislocation motion. Therefore, the maximum resolved shear stress intensity coefficient, RSSIC, on the crack plane (also a slip plane) is proposed as a parameter to characterize the shear crack growth.

Figure 18 shows the maximum RSSIC on the slip system (111) [101] of Specimen R3 v.s. crack lengths, a'/W. The crack growth rate, da/dN, is plotted as a function of $\triangle R S S I C$ in Figure 19.

\section{DISCUSSIONS}

The finite element calculations for the crack tip stress fields are made for an isotropic solid. However, the aluminum crystal is 
anisotropic with a cubic symmetry and the inclined crack needs a threedimensional model. However, the calculations made in this study should be able to include the essential features of the crack tip stress field and to cover the primary effects on the crack tip slip systems.

A crack tip slip system will be activated and shear decohesion will take place only if its resolved shear stress intensity exceeds a certain critical value. The resolved shear stress intensity is Inearly proportional to the applied nominal k-value. For a specific crack geometric configuration, at a low level of the nominal $k$, there might be only one slip system activated, while at a higher level of the nominal $\mathrm{K}$, two or more slip systems might be activated. The detailed shear decohesion process and the crack surface morphology depends on the orientations of the active slip systems and their relative contributions to the overall crack growth process.

It is reasonable to expect that shear crack growth should correlate well with RSSIC. The crack growth rate correlation with the calculated RSSIC, Figure 19, is primarily for Mode III shear crack with a minor Mode II component. It remains to be seen whether the sarne correlation is equally applicable to Mode II, Mode III, and all of the combined shear mode crack growth.

Fatigue crack growth on two or more slip planes might be related to a combination of the RSSIC's of the active slip systems. It is evident that a large amount of information is needed to answer all of these questions. It is hoped that this promissing preliminary study will lead to a large effort in the basic study of the fatigue crack growth mechanism. 
1. Fatigue crack growth is caused primarily by shear decohesion at a crack tip, which is the result of the dislocation motion and is controlled by the resolved shear stresses on the active crack-tip slip systems.

2. Fatigue tests were conducted on Al 7029 large grain poly-crystals. The crack paths were generally irregular and zigzag. The crack tip stress field is calculated with the finite element method. The crack tip resolved shear stresses are computed, and the resolved shear stress intensity coefficient, RSSIC, is defined and the values for each test specimens are evaluated.

3. When the RSSIC on a single slip system is much higher than all the others, the crack will follow a single slip-plane.

4. When the RSSIC's on two conjugate slip systems are comparable, a crack will grow in a zigzag manner on these planes, and the macro-crack-plane bisects these two active slip-planes.

5. The maximum RSSIC on the most active slip system is proposed as a parameter to correlate with the shear fatigue crack growth rate in large crystals. 
A compact tension specimen with its coordinate systems is shown schematlcally in the figure below. $x_{1}$ are the coordinates with the origin at the notch tip and $x_{1}$ along the notch line. The origin of the $x_{1}^{\prime}$ coordindates is at the crack tip. In the two-dimenional plane, $x_{1}^{\prime}$ is along the crack line and $x_{2}^{\prime}$ is normal to the crack line.
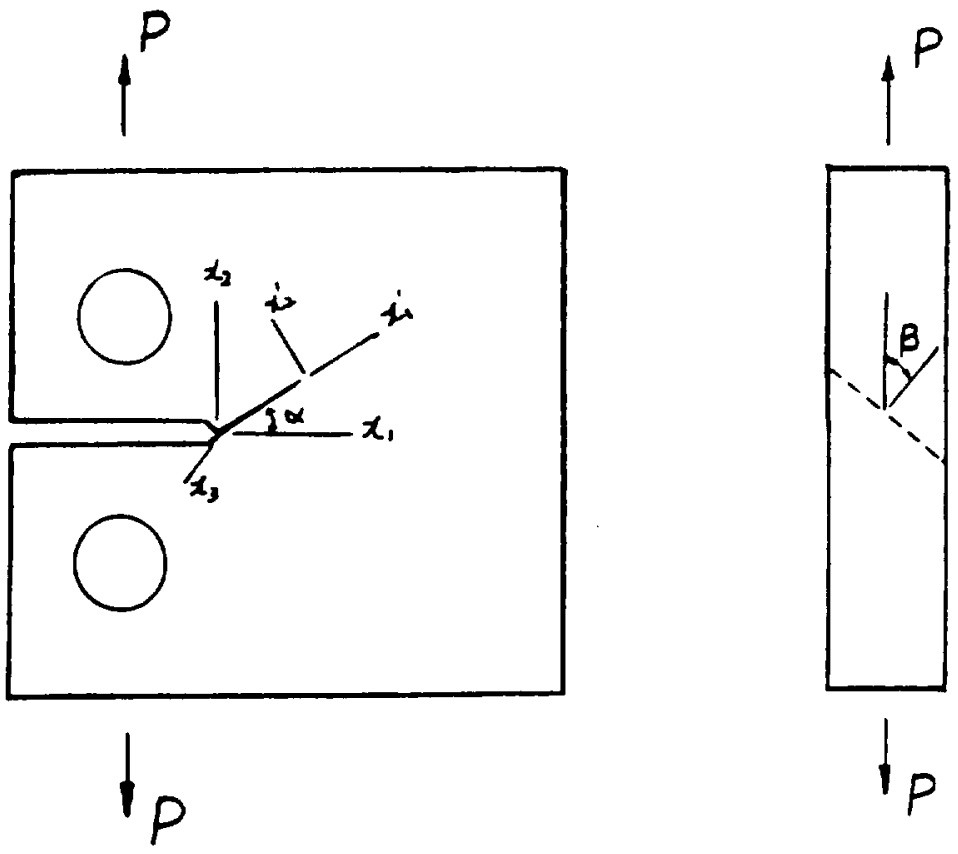

Since the crack plane is inclined to the loading axis and it is also inclined to the $x_{1}^{\prime}-x_{2}^{\prime}$ plane, the crack tip stress field is a combination of Mode I, II, and III. Thus, the crack tip stresses, referring to the $x_{1}^{\prime}$-coordinates, are prescribed by $K_{I}^{\prime}, K_{I}^{\prime}$, and $K_{I I}^{\prime}$.

with a through crack and with the crack plane perpendicular to the $x_{1}^{\prime}-x_{2}^{\prime}$ plane, the two-dimensional $K_{I}$ and $K_{I I}$ can be calculated with FEM. However, if the crack plane is inclined to the $x_{1}^{\prime}-x_{2}^{\prime}$ plane, in addition, $K_{I I I}^{\prime}$ exists also. By resolving the applied stress onto the crack plane, Pook [20] and Chan and Cruse [21] approximated the crack tip field for the inclined crack from the two dimensional crack tip field of $K_{I}$ and $K_{\Pi}$ :

$$
\begin{aligned}
& K_{I}^{\prime}=K_{I} \cos ^{2} \beta \\
& K_{I I}^{\prime}=K_{I I} \cos \beta
\end{aligned}
$$




$$
K^{\prime}{ }_{I I}=K_{t} \cos \beta \sin \beta
$$

$\beta$ is the angle of the inclination defined in the above figure.

The crack tip stresses in the $x_{1}^{\prime}$ coordinates system are therefore given by [27]

$$
\begin{aligned}
& \sigma_{x^{\prime} x^{\prime}}=\frac{\mathrm{K}_{\mathrm{I}}^{\prime}}{\sqrt{2 \pi \mathrm{r}}} \cos \frac{\theta}{2}\left[1-\sin \frac{\theta}{2} \sin \frac{3 \theta}{2}\right]-\frac{K_{\mathrm{II}}^{\prime}}{\sqrt{2 \pi \mathrm{r}}} \sin \frac{\theta}{2}\left[2+\cos \frac{\theta}{2} \cos \frac{3 \theta}{2}\right] \\
& \sigma_{y^{\prime} y^{\prime}}=\frac{K_{I}^{\prime}}{\sqrt{2 \pi r}} \cos \frac{\theta}{2}\left[1+\sin \frac{\theta}{2} \sin \frac{3 \theta}{2}\right]+\frac{K_{\Pi}^{\prime}}{\sqrt{2 \pi r}} \sin \frac{\theta}{2} \cos \frac{\theta}{2} \cos \frac{3 \theta}{2} \\
& \tau_{x}{ }_{y},=\frac{K_{I}^{\prime}}{\sqrt{2 \pi r}} \sin \frac{\theta}{2} \cos \frac{\theta}{2} \cos \frac{3 \theta}{2}+\frac{K_{I I}^{\prime}}{\sqrt{2 \pi r}} \cos \frac{\theta}{2}\left[1-\sin \frac{\theta}{2} \sin \frac{3 \theta}{2}\right] \\
& \tau_{x}^{\prime z^{\prime}}=-\frac{\mathrm{K}_{\mathrm{II}}^{\prime}}{\sqrt{2 \pi x}} \sin \frac{\theta}{2}, \tau_{y^{\prime} z^{\prime}}=\frac{\mathrm{K}_{\mathrm{III}}^{\prime}}{\sqrt{2 \pi x}} \cos \frac{\theta}{2} \\
& \sigma_{z} y^{\prime}=v\left(\sigma_{x} x^{\prime}+\sigma_{y}^{\prime y}{ }^{\prime}\right) .
\end{aligned}
$$

Now, let $x_{1}^{\prime \prime}$ be the local coordinates at the crack tip, and $x_{1}^{\prime \prime}$ coinclde with the principal axes of the crystal, i.e. $\mathbf{x}_{1}^{\prime \prime}$ in the direction of $[100] ; x_{2}^{\prime \prime},[010] ;$ and $x_{3}^{\prime \prime},[001]$. At any local point, the stress components in the direction of the principal axes of the crystal can be denoted as $\sigma_{1}{ }^{\prime} "$. They are given simply by transforming $\sigma_{1}, j$ ' into the directions of the crystal axes:

$$
\sigma_{1}, 1 *=\left[C_{1},, j\right]\left[\sigma_{1},, j\right]\left[C_{1}, 1,\right]^{T}
$$

where $\left[C_{1}, y_{1}\right]$ is an $3 \times 3$ matrix, whose componenets are the direction cosines between $x_{j}^{\prime}$ and $x_{1}^{\prime \prime}$ axes. $\left[\sigma_{1}, j_{1}\right]$ is an stress matrix, whose components are given by Equation $\mathrm{A} 4$.

The resolved shear stress is given by [22]

$$
\tau_{R S S}=\frac{1}{b} b_{1} \sigma_{1}, n_{j}
$$

where $b_{1}$ is the Burgers vector, and $n_{1}$ is the unit normal vector of the pertinent slip plane. For a FCC crystal, $b_{1}$ is along $\langle 110\rangle$, and $n_{j}$ is 
along <111>. Substituting Equation A5 into Equation A6, the resolved shear stress in matrix form is

$$
\tau_{R S S}=\left[b_{1} n\right]\left[c_{1}, j,\right]\left[\sigma_{1}, j\right]\left[c_{1},,\right]^{T}\left[n_{1} n\right]
$$

Since the components of $\left[\sigma_{1}, 1,\right]$ are a function of $K_{I}^{\prime}, K_{I}^{\prime}, K_{I I}^{\prime}$, and $\theta$, at a given local point near the crack tip, $\left[\sigma_{1}, y,\right]$ can be abbreviated as

$$
\left[\sigma_{1},,\right]=\frac{1}{\sqrt{2 \pi r}}\left[K_{I}^{\prime}, K_{I I}^{\prime}, K_{I I}^{\prime}, f(\theta)\right] \text {. }
$$

Hence, the resolved shear stress can be written as

$$
\tau_{R S S}=\frac{1}{\sqrt{2 \pi x}}\left[b_{1} n\right]\left[c_{1, y,}\right]\left[K_{1}^{\prime}, K_{I I}^{\prime}, K_{I I}^{\prime}, f(\theta)\right]\left[C_{1},_{,}\right]^{T}\left[n_{f}\right]
$$

$b_{1}, n_{1}$ and $\theta$ are related. Once $b_{1}$ and $n_{1}$ are given, $\theta$ is determined. We define the resolved shear stress intensity coefficient (RSSIC) as

$$
\operatorname{RSSIC}=\left[b_{1} n\right]\left[C_{1} n_{1}\right]\left[K_{I}^{\prime}, K_{I I}^{\prime}, K_{I I}^{\prime}, f(\theta)\right]\left[C_{1} n_{1}\right]^{T}\left[n_{f} n,\right.
$$

such that

$$
\tau_{\mathrm{RSS}}=\frac{\mathrm{RSSIC}}{\sqrt{2 \pi r}}
$$

RSSIC is in the unit of MPa $V_{m}$ or KSIVin. 


\section{ACKNOWLEDGEMEN'T}

The work was conducted at the George Sachs Fracture and Fatigue Research Laboratory of the Department of Mechanical and nerospace Engineering, syracuse Unversity. The financial support by NASA Lewis Research Center, Grant No. NAG 3-348 is acknowledged. The help of the Hibbit, Karlsson, and Sorensen, Inc. for the privilege of using the ABAQUS finite element program is also acknowledged. The authors would like to thank Dr. Harry Sang at the Kingston Laboratories of Alcan International Limited and Dr. Tax Stock of Alcan Rolled Products

Company at oswego, N.Y. to provide the aluminum alloy. The discussions with Mr. Jack Telesman and Dr. Louis Ghosn during the course of the study is deeply appreciated. 


\section{REFERENCES}

[1] P. J. E. Forsyth, Crack Propagation Symp., College of Aeronautics, Cranfield, Beds. England, Vol. 1, 1961, p. 76.

[2] P. Nuemann, Z. Metallkde, Vol. 58, 1967, p. 780 .

[3] P. Nuemann, Acta Met., Vol. 22, Sept. 1974, p. 1155.

[4] H. Vehoff and P. Nuemann, Acta Met., Vol. 27, 1979, pp. 915-920.

[5] A. S. Kuo and H. W. Liu, Scripta Met., Vol. 10, 1976, pp. 723-728.

[6] C. Y. Yang and H. W. Liu, Scripta Met., Vol. 14, 1980 , PP. 785-790.

[7] H. W. Liu, to be published, Oct. 1987.

[8] M. Gell and G. R. Liverant, Acta Met., Vol. 16, April 1968 , pp. 553-561.

[9] M. Gell and G. R. Liverant, Trans. AIME, Vol. 242, Sept. 1968, pp. 1869-1879.

[10] D. J. Duquette, M. Gell, and J. W. Piteo, Met. Trans., Vol. 1, Nov. 1970 , pp. 3107-3115.

[11] $0 . Y$. Chen, Ph.D Dissertation, The University of Connecticut, 1985 .

[12] K. S. Chan, J. E. Hack, and G. R. Liverant, Met. Trans., Vol. 18A, April 1987, pp. 581-591.

[13] M. Nageswararao and V. Gerold, Met. Trans., Vol. 7A, Dec. 1976, pp. 1847-1855.

[14] W. Vogel, M. Wilhelm, and V. Gerold, Acta Met., Vol. 30, 1982, pp. 21-35.

[15] A. J. McEvily, Jr. and R. C. Boettner, Acta Met., Vol. 11, July 1963, pp. 725-743.

[16] Z. X. Tong, L. Liu, S. Lin, and C. M. Hsiao, Scripta Met., Vol. 20, 1986, pp. 967-982.

[17] H. I. Kaplan and C. Laird, Trans. AIME, Vol. 239, July 1967, pp. 1017-1025.

[18] J. Schijve, Fatigue Crack Propagation, ASTM STP 415, Am. Soc. Testing Mats., 1967, pp. 415-457.

[19] Gerhard Maurer and H. W. Liu, Fatigue 84, Vol. I, Sept. 1984, pp. 297-306. 
[20] L. P. Pook, Engineering Fracture Mechanics, Vol. 3, No. 3, oct. 1971, pp. 205-218.

[21] K. S. Chan and T. A. Cruse, Engineering Fracture Mechanics, Vol. 23, No. 5, 1986, pp. 863-874.

[22] M. D. Peach and J. S. Koehler, Phys. Rev., Vol. 80, 1950, pp. 436-439.

[23] C. Laird, Fatigue Crack Propagation, ASTM STP 415, Am. Soc. Testing Mats., 1967, pp. 131-168.

[24] R. M. N. Pelloux, Trans. ASM, Vol. 62, 1969, pp. 281-285.

[25] B. Tomk1ns, phil. Mag., Vol. 18, No. 155, 1968, p. 1041.

[26] E. Orowan, Rep. Prog. Phys., Vol. 12, 1949, p. 185.

[27] P. C. Paris and G. C. Shi, Fracture Toughness Testing and Its Applications, ASTM STP 381, Am Soc. Testing Mat., 1965, pp. $30-81$. 
Table 1. RSSIC Values of 12 Slip Systems for Specimen R3

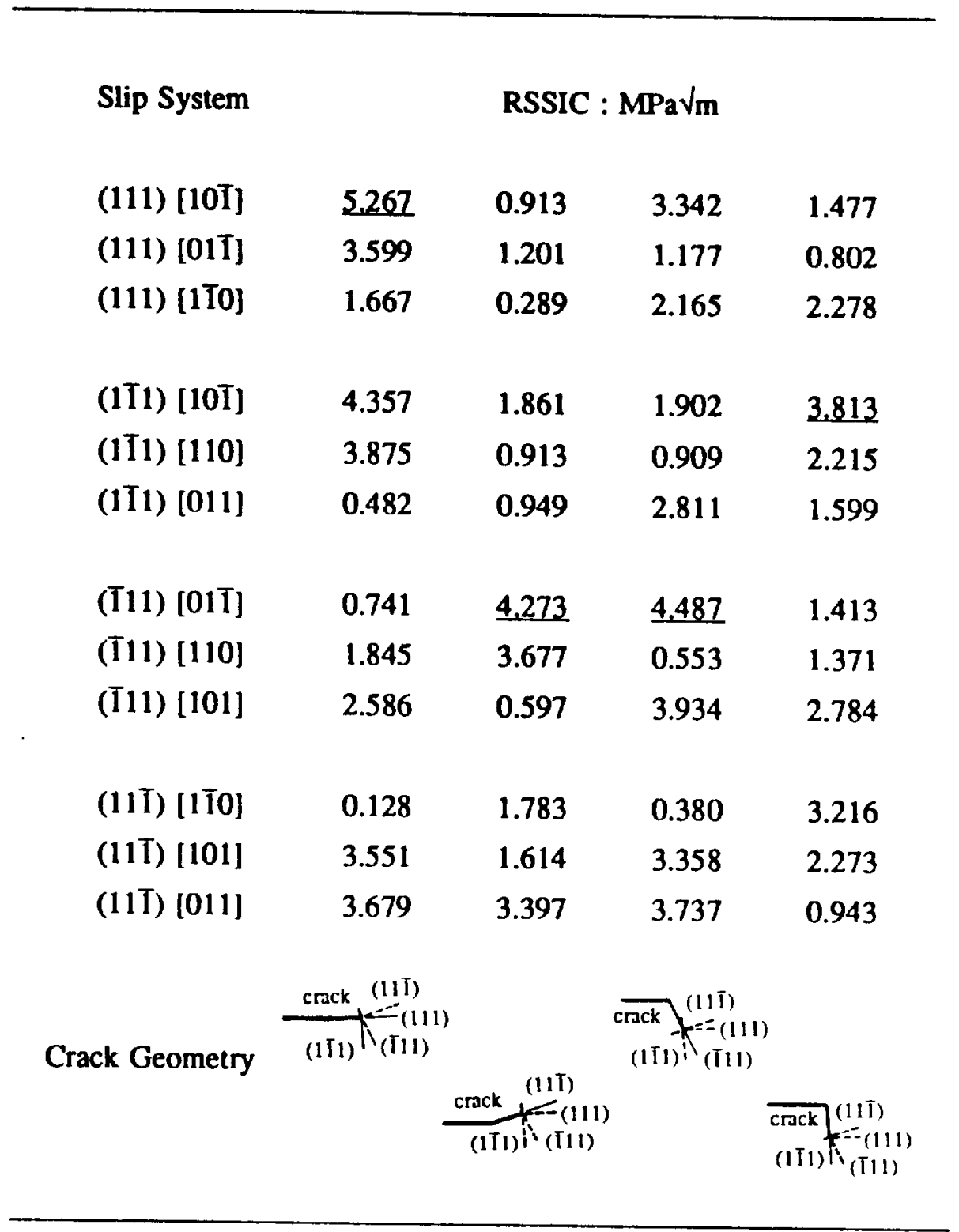


Table 2. RSSIC Values of 12 Slip Systems for Specimen R4

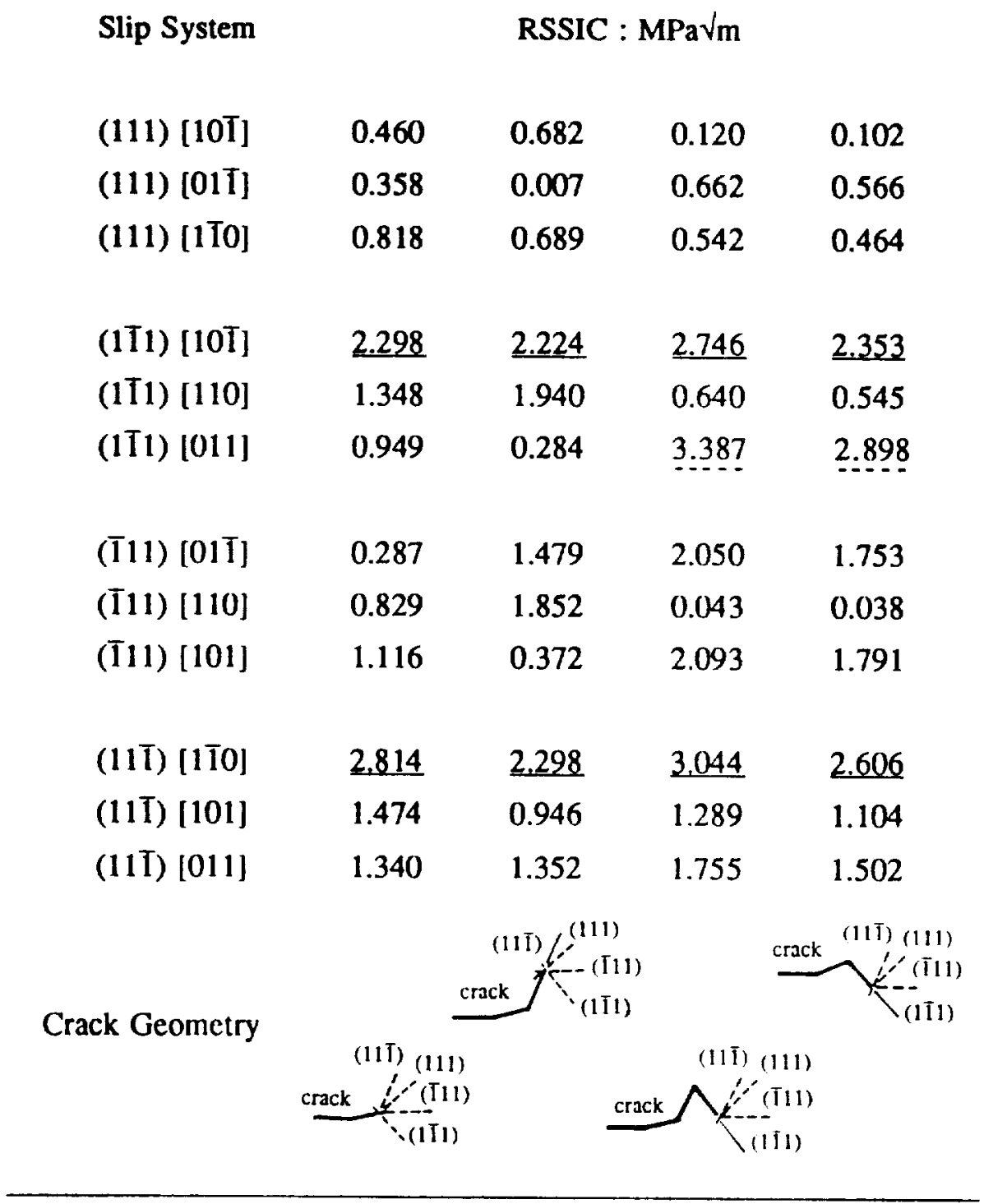


Table 3. RSSIC Values of 12 Slip Systems for Specimen R5

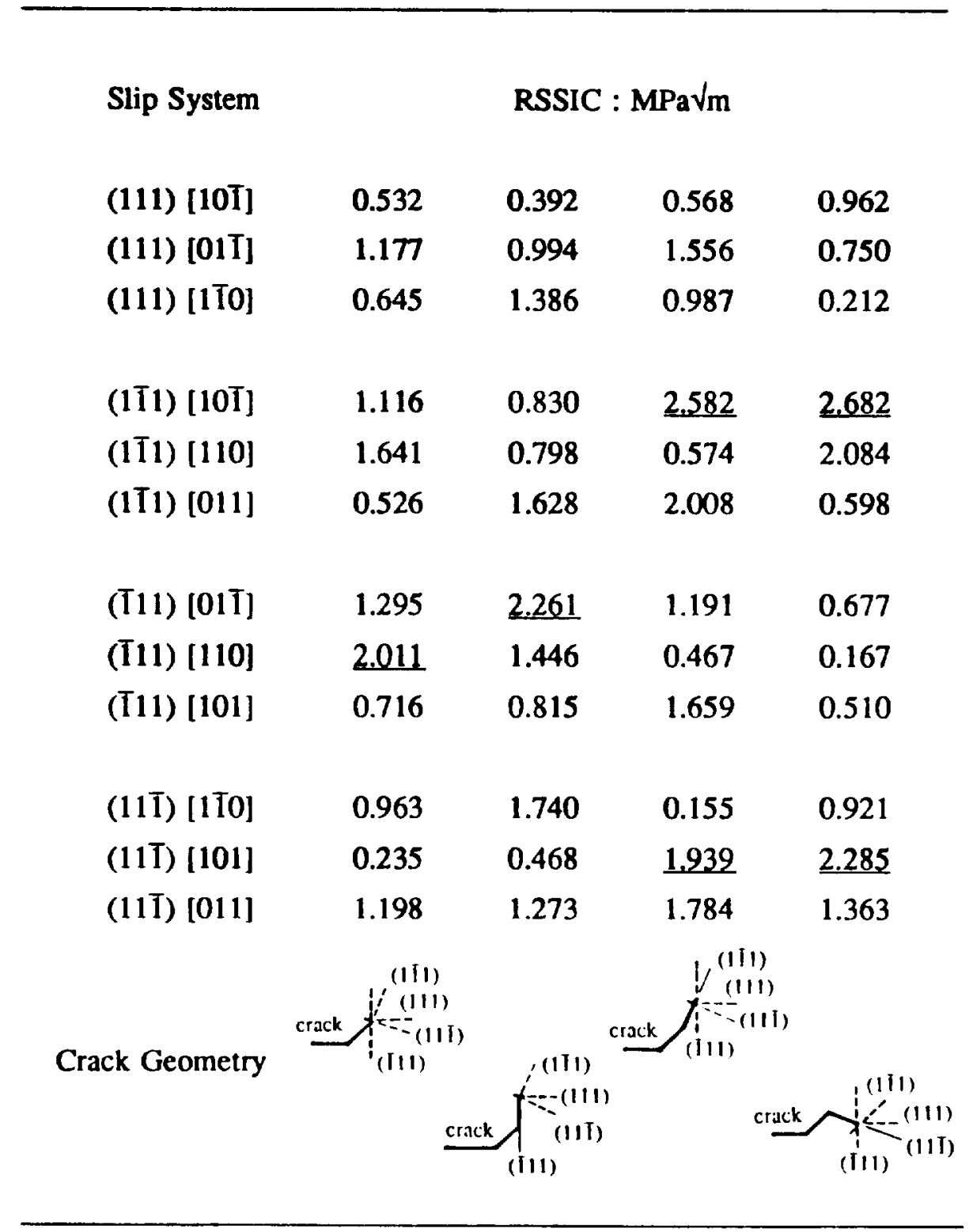




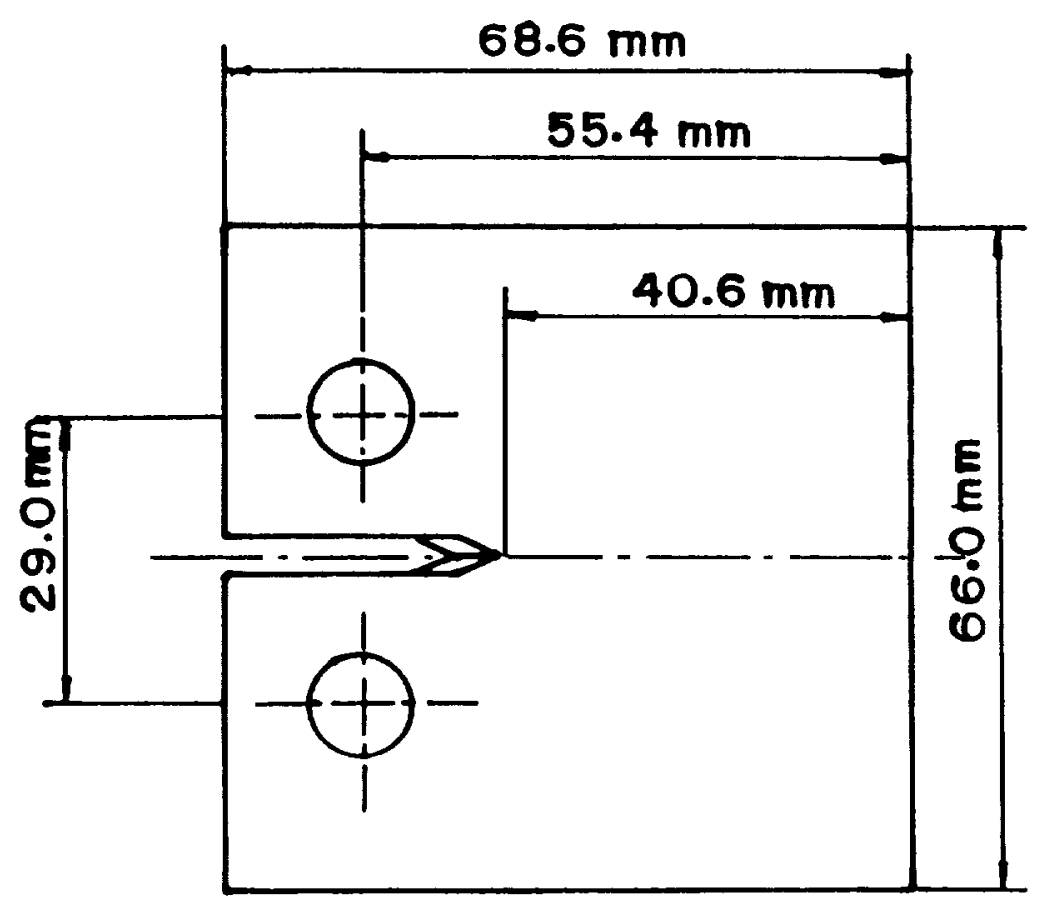

Fig. 1 Dimensions of compact tension specimen. 
WUINAL EOS IS
OF POOR QU. LITY

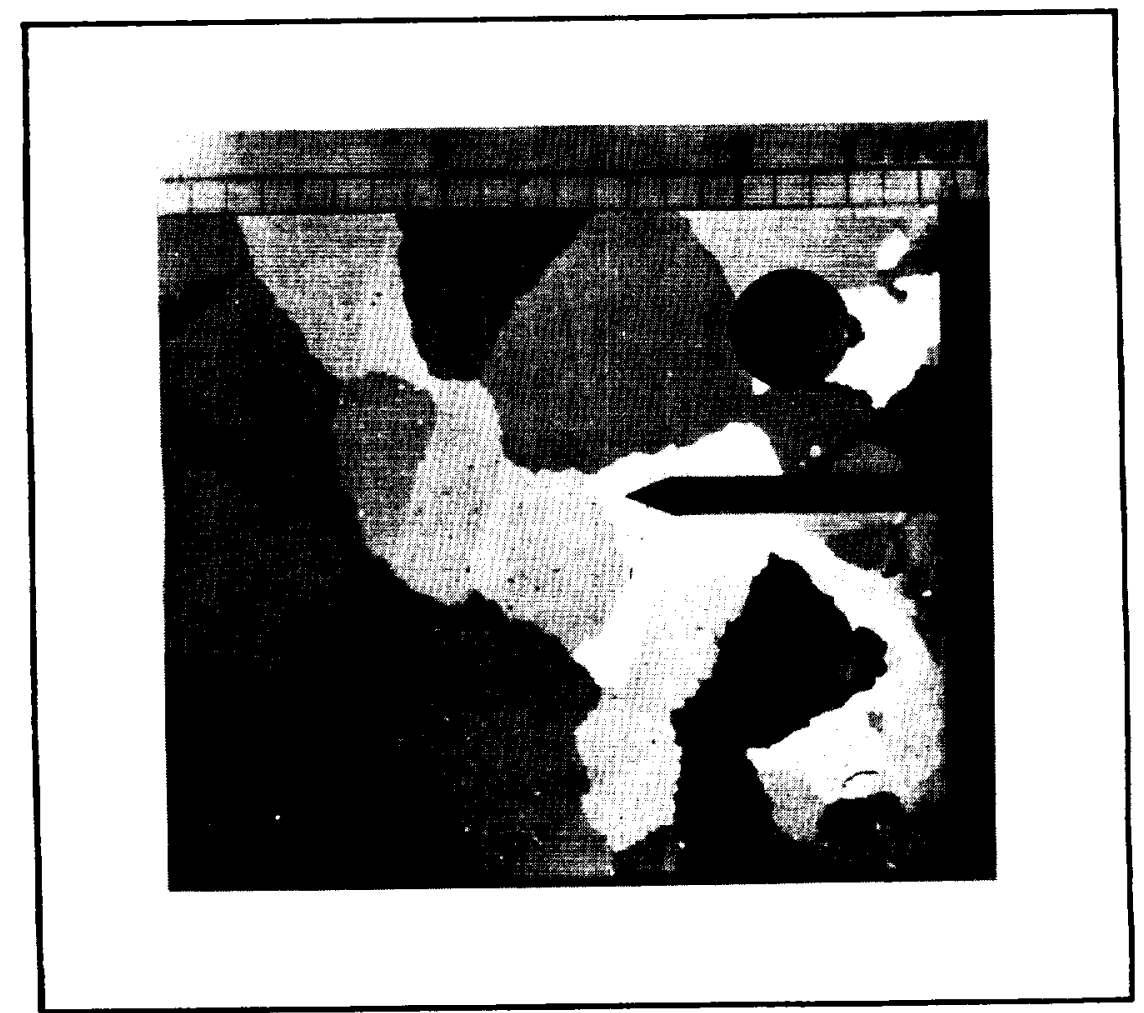

Fig. 2 The photograph of a compact tension specimen with large grains. 


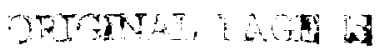

$$
\begin{aligned}
& y=\text { vo Quverry }
\end{aligned}
$$

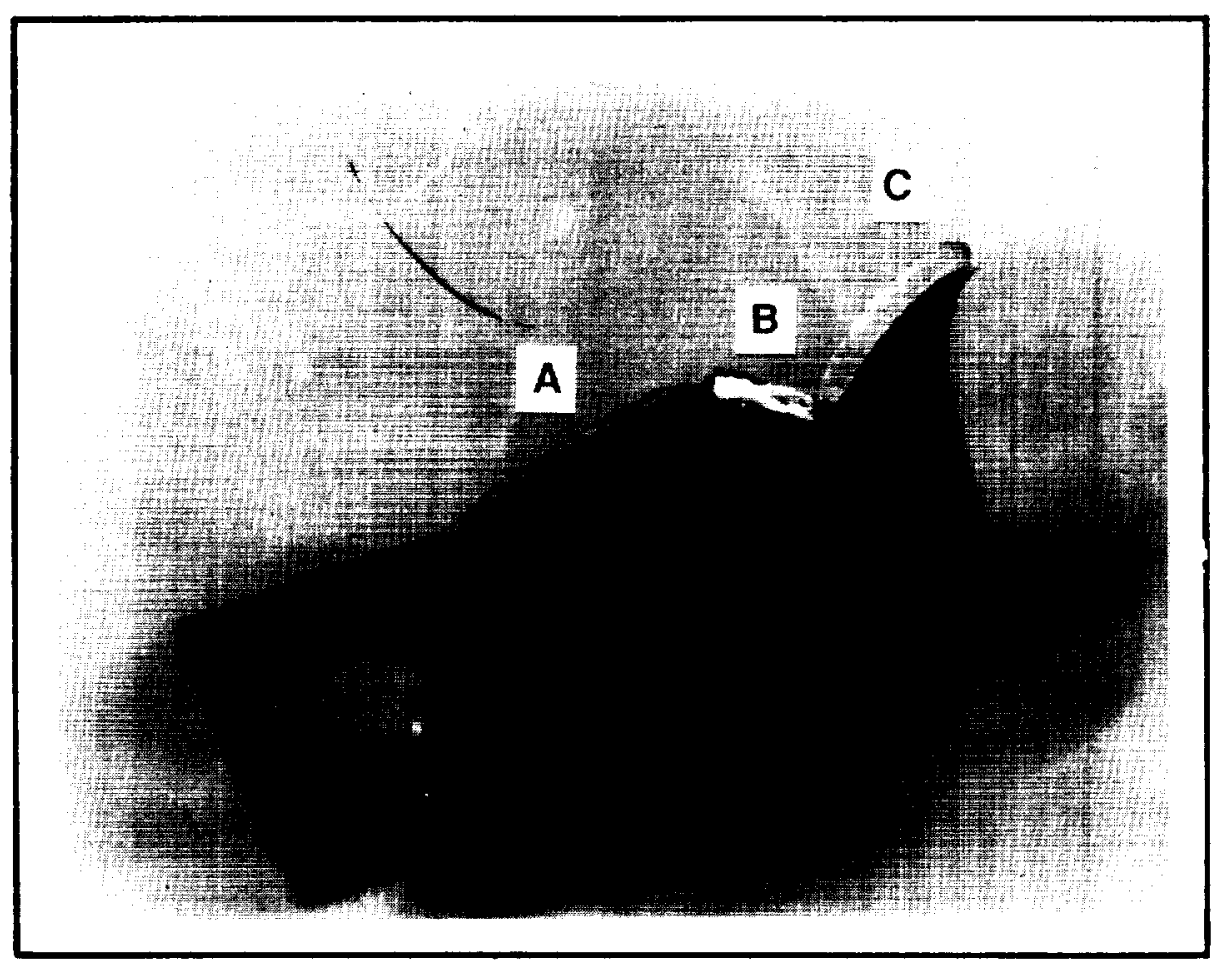

(3a.i) Photograph of the fractured specimen R1.

Fig. 3 Photograph and sketches of fracture surfaces and grain structures of specimens. 


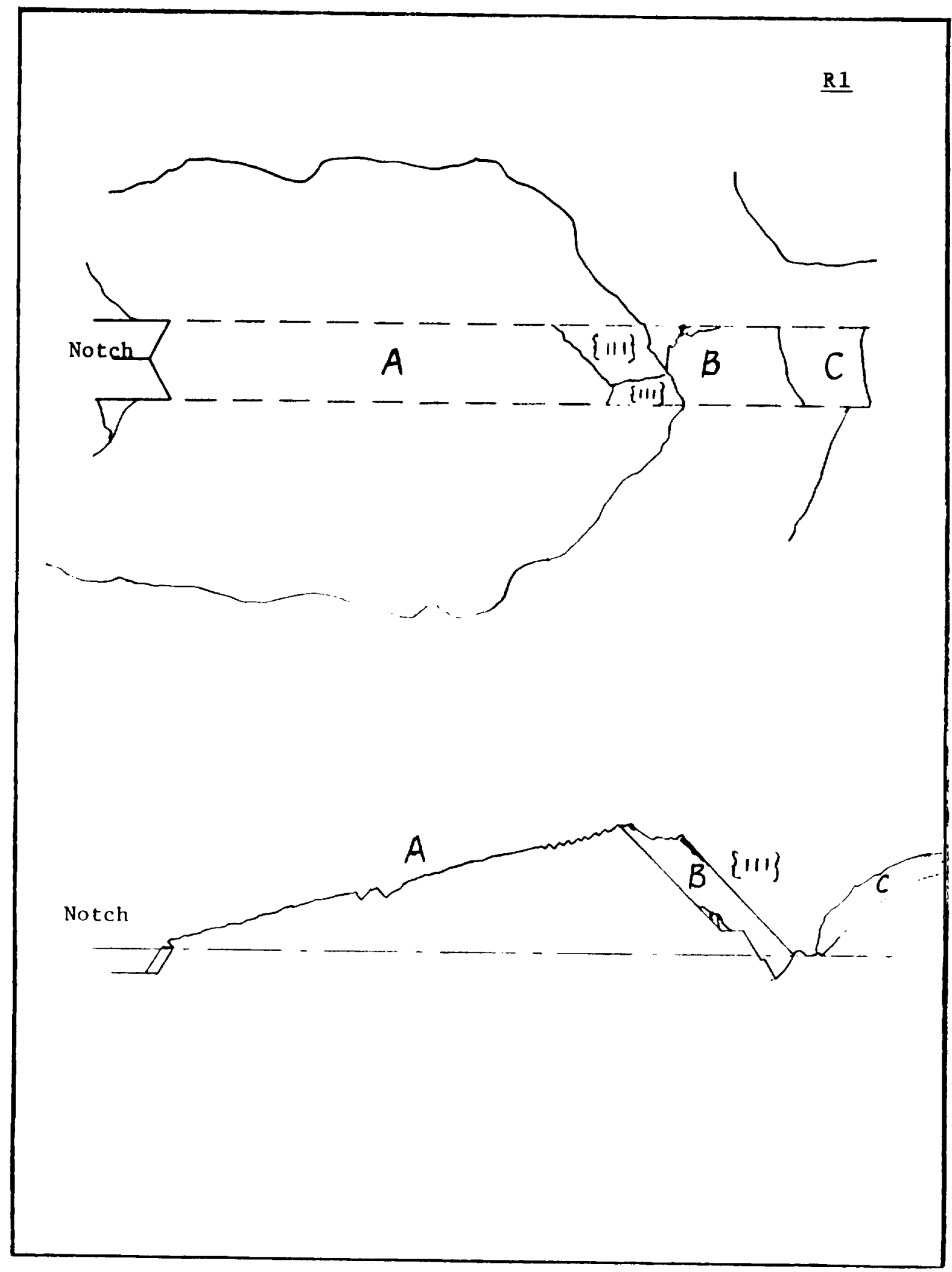

(3a.ii) The sketch of the fracture surface of Specimen R1. 


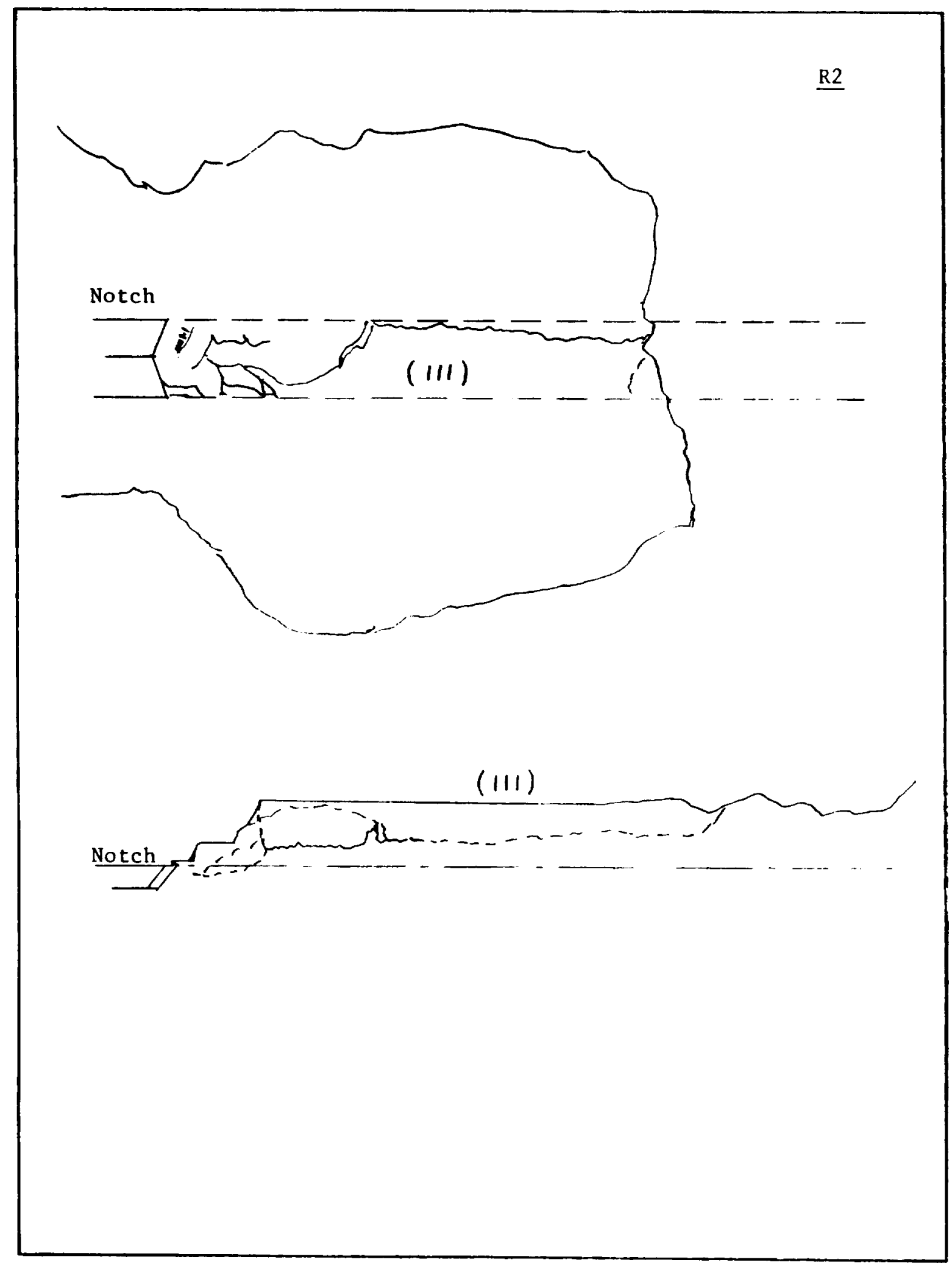

(3b) The sketch of the fracture surface of Specimen R2. 


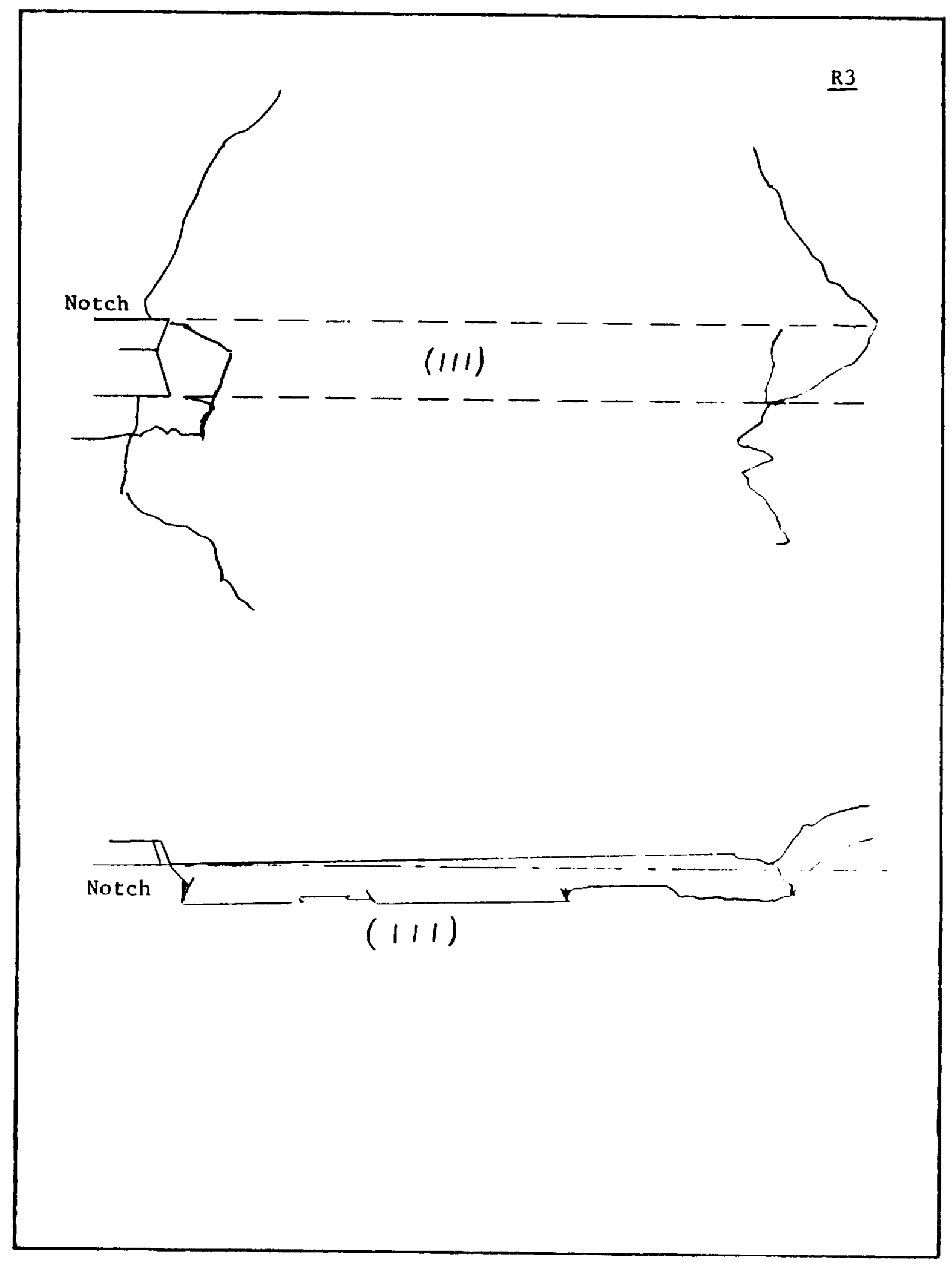

(3c) The sketch of the fracture surface of Specimen R3. 


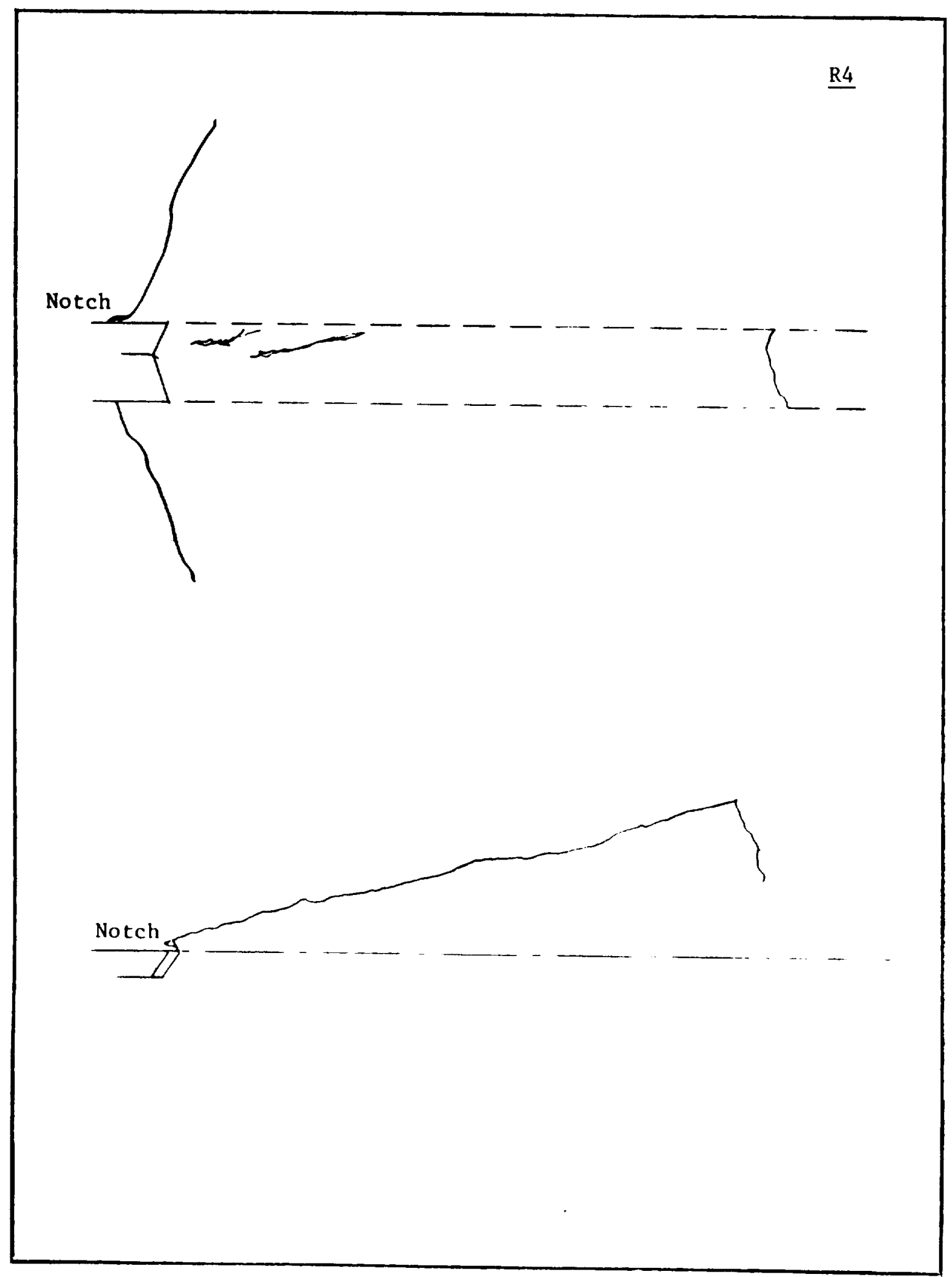

(3d) The sketch of the fracture surface of Specimen R4. 


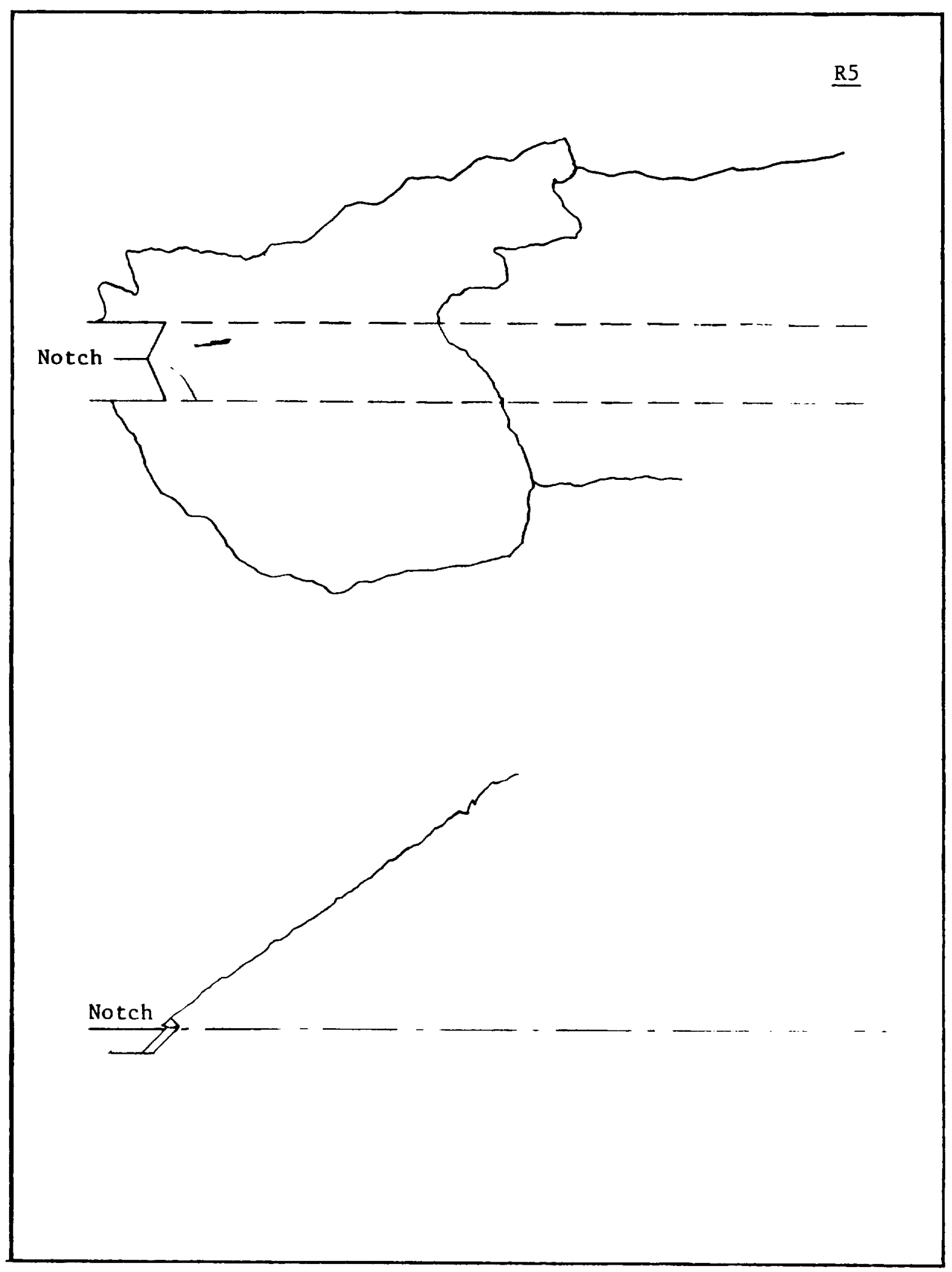

(3e) The sketch of the fracture surface of Specimen R5. 


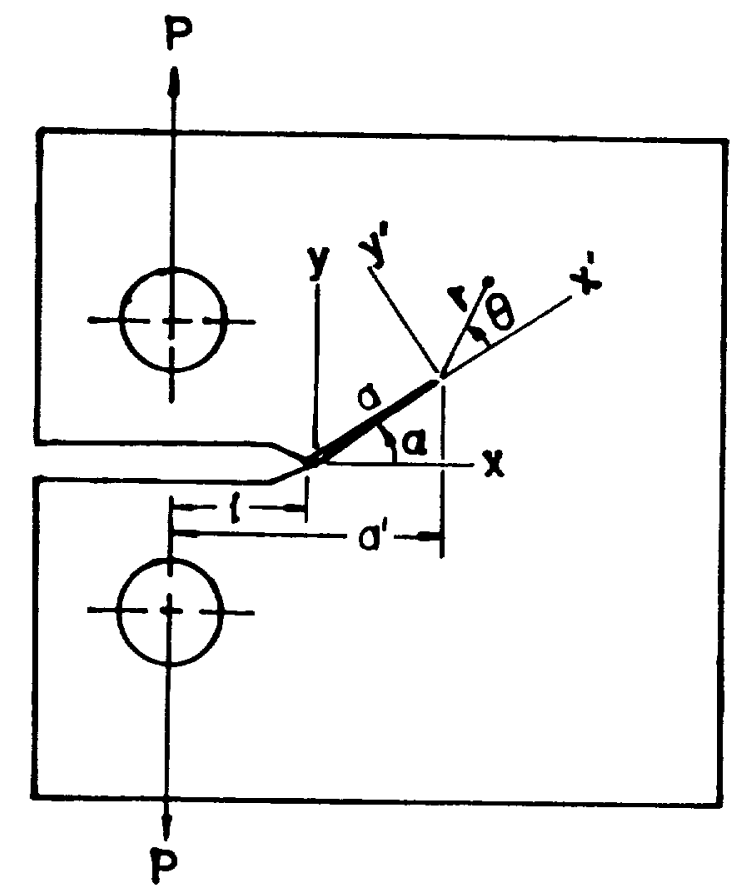

Fig. 4 A compact tension specimen with an inclined crack and its coordinate systems. 


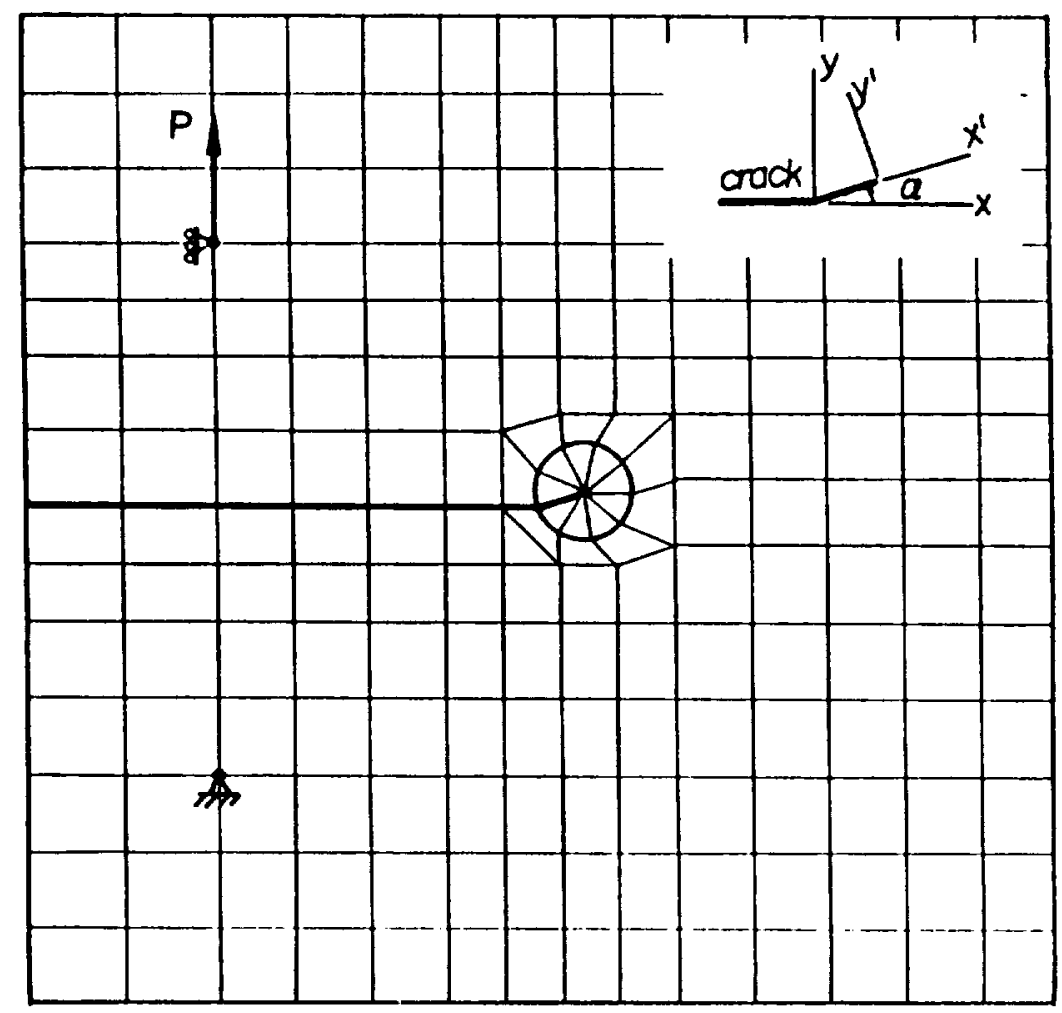

(a)

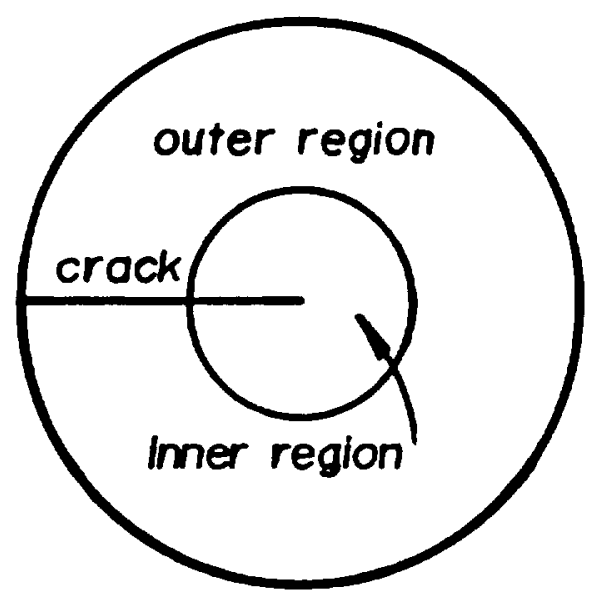

(b)

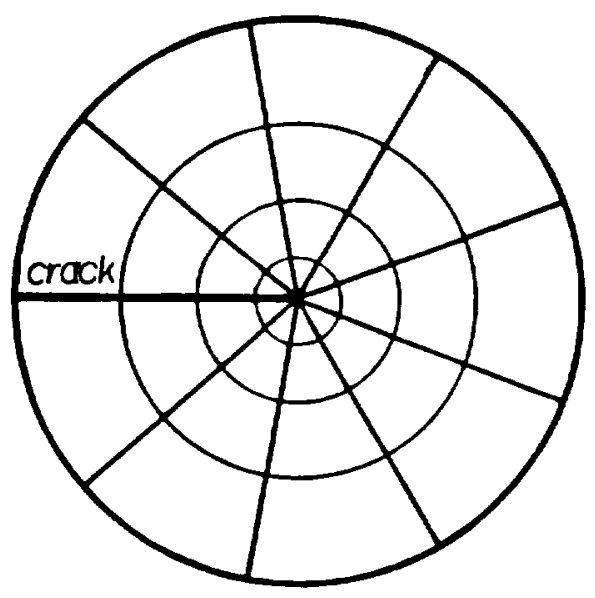

(c)

Fig. 5 (a) A FEM mesh for a compact tension specimen with an inclined crack.

(b) Crack tip mesh contains two regions. (c) The details of the inner region. 


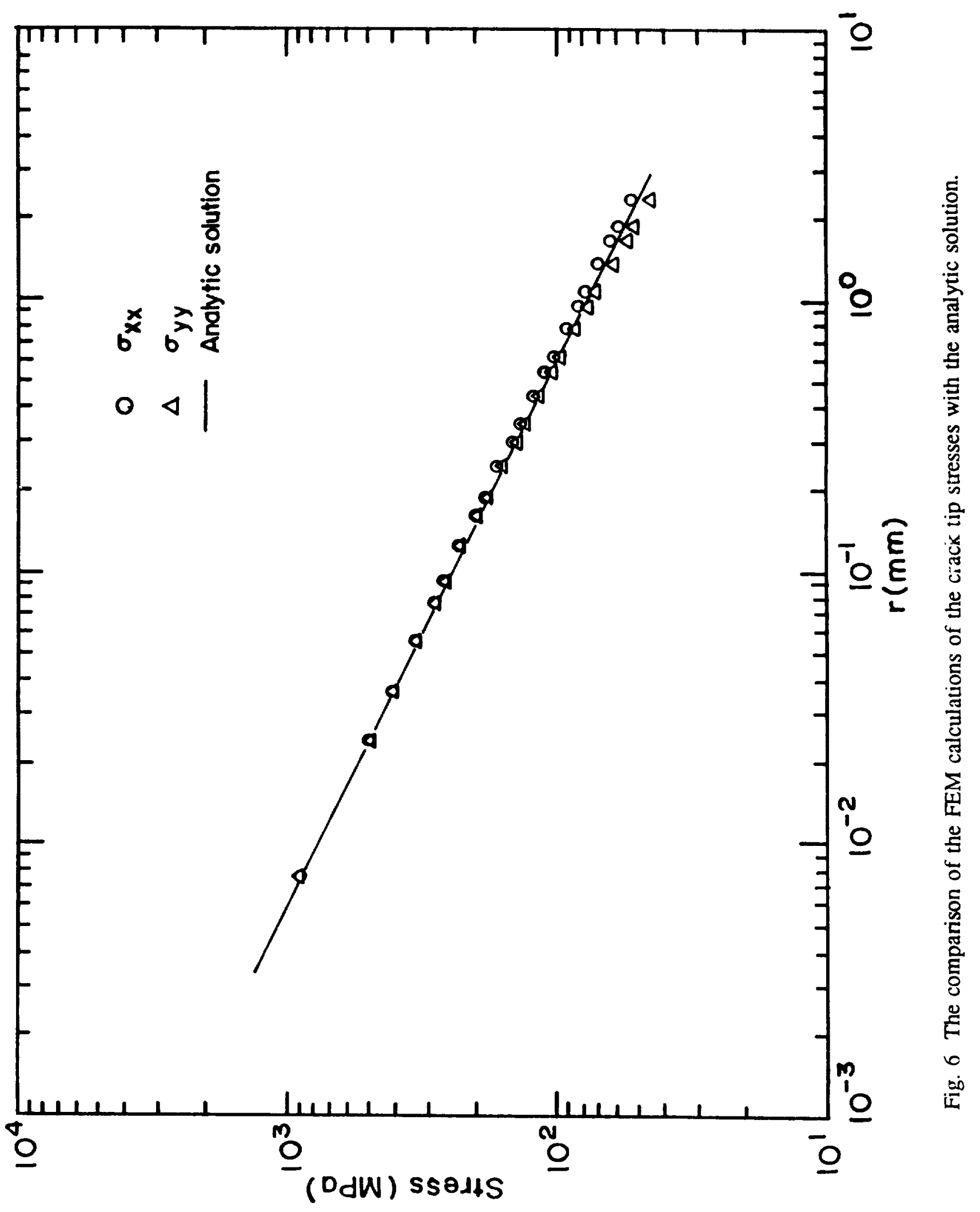




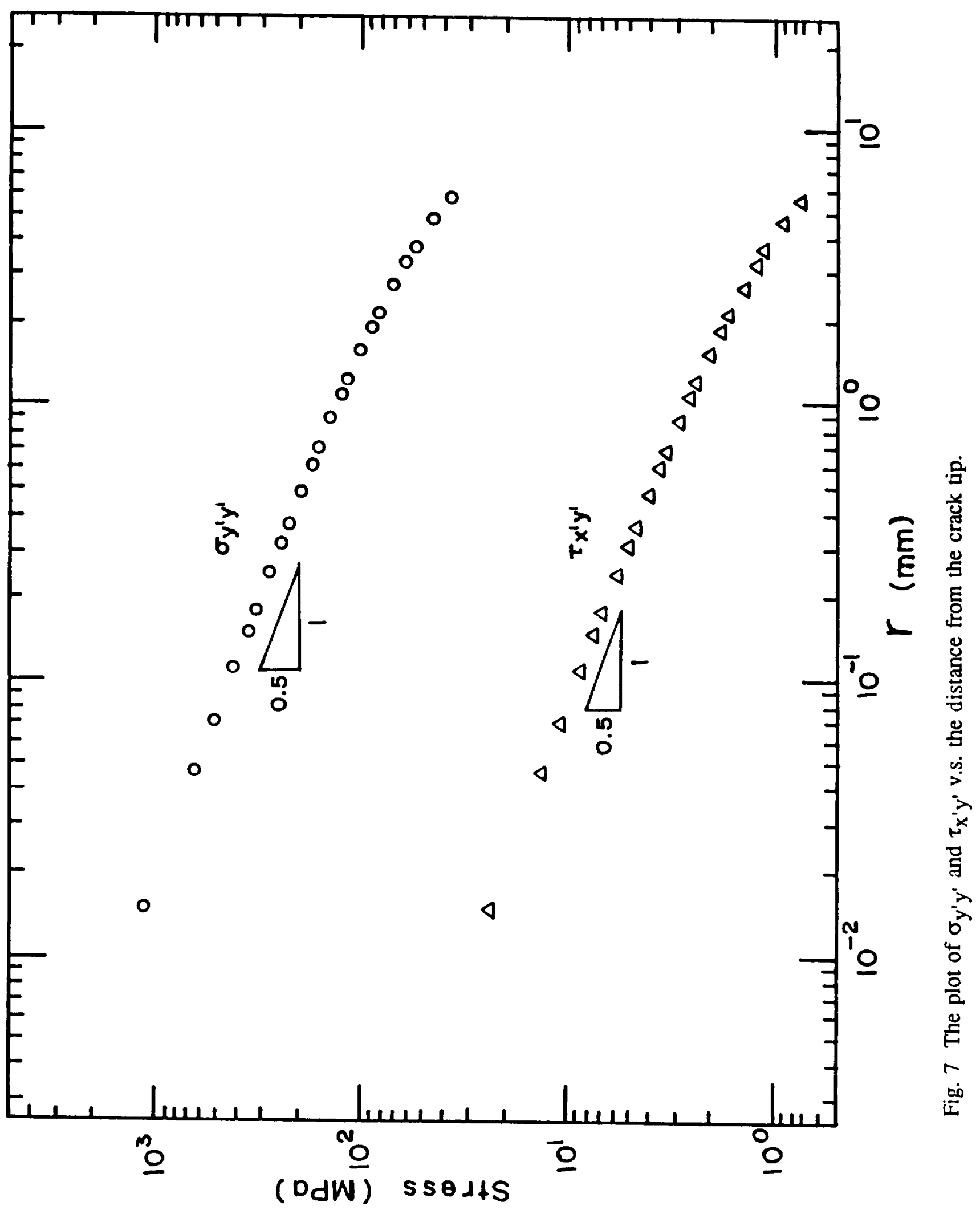




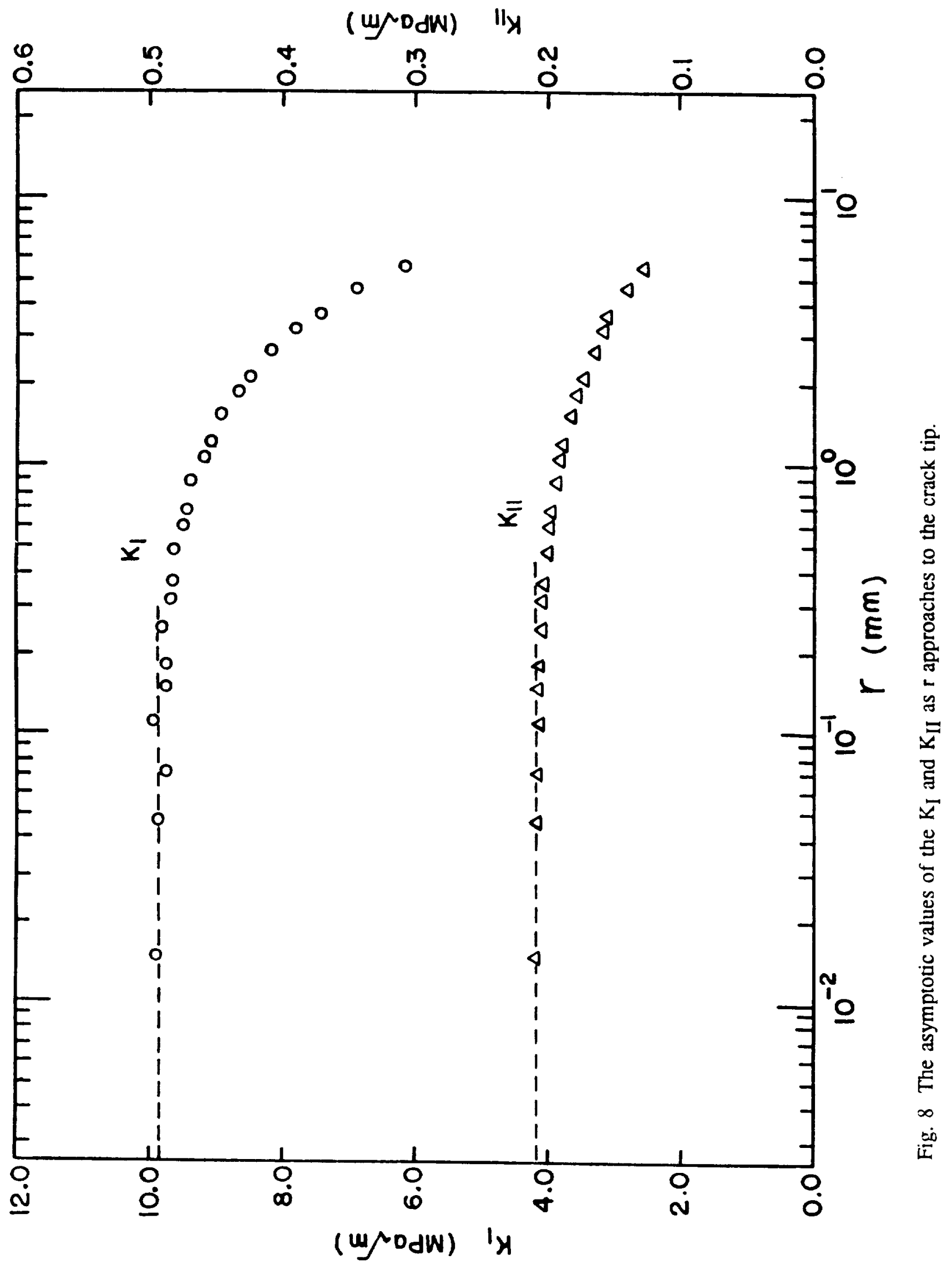



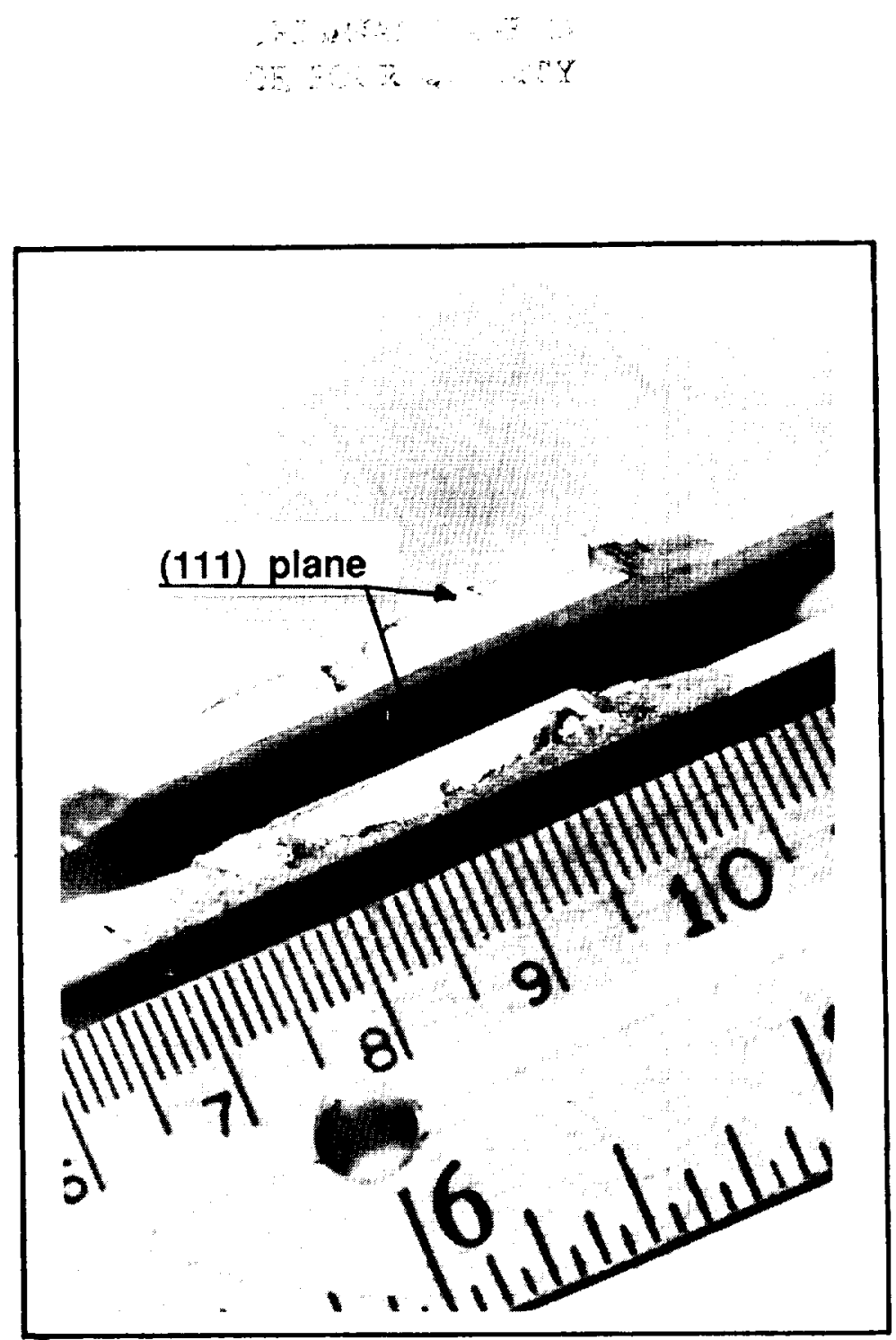

Fig. 9 Photograph of Specimen R2 and R3 with (111) slip-plane fracture surfaces. 


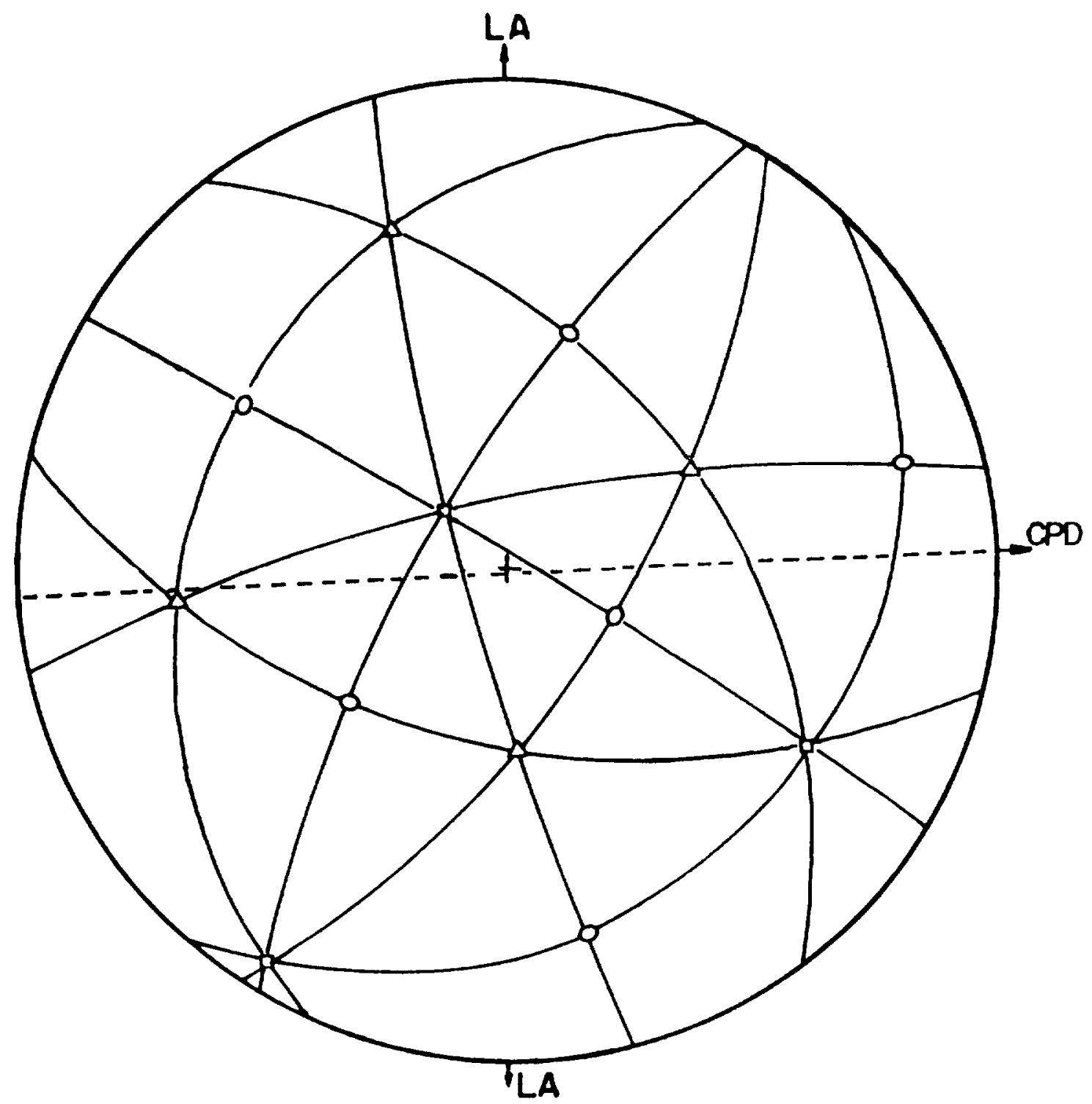

Fig. 10 The stereographic projection of the crystal at the crack tip in Specimen R3. 


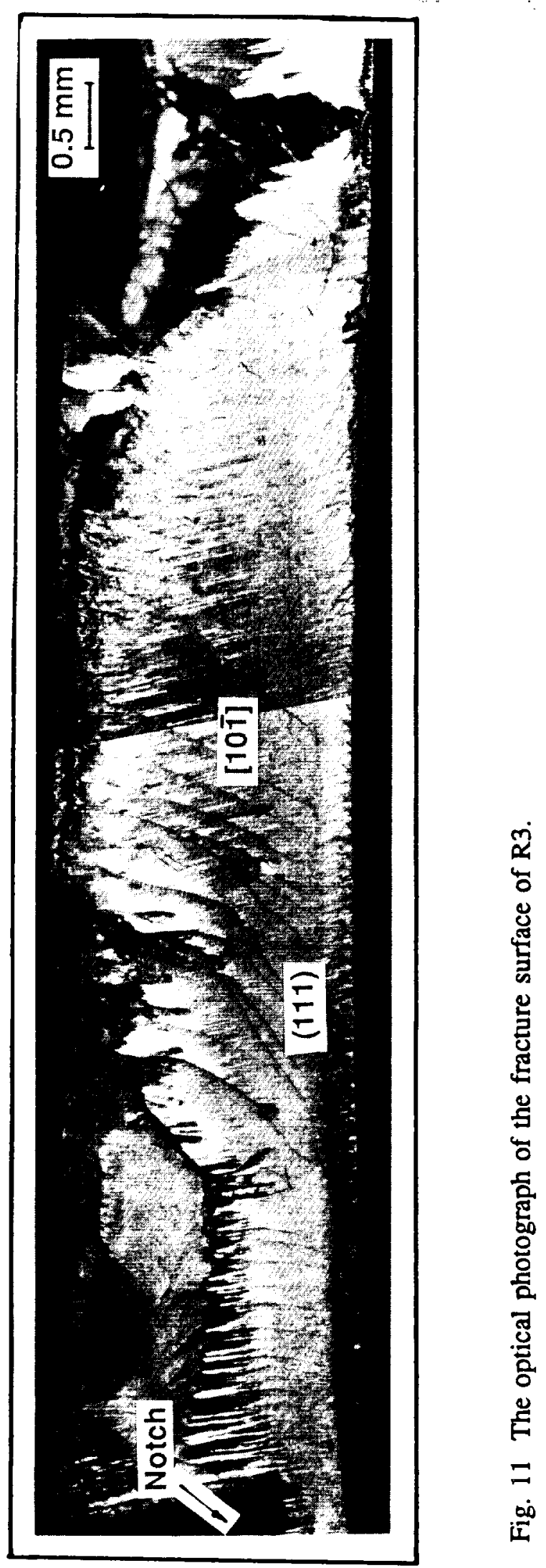



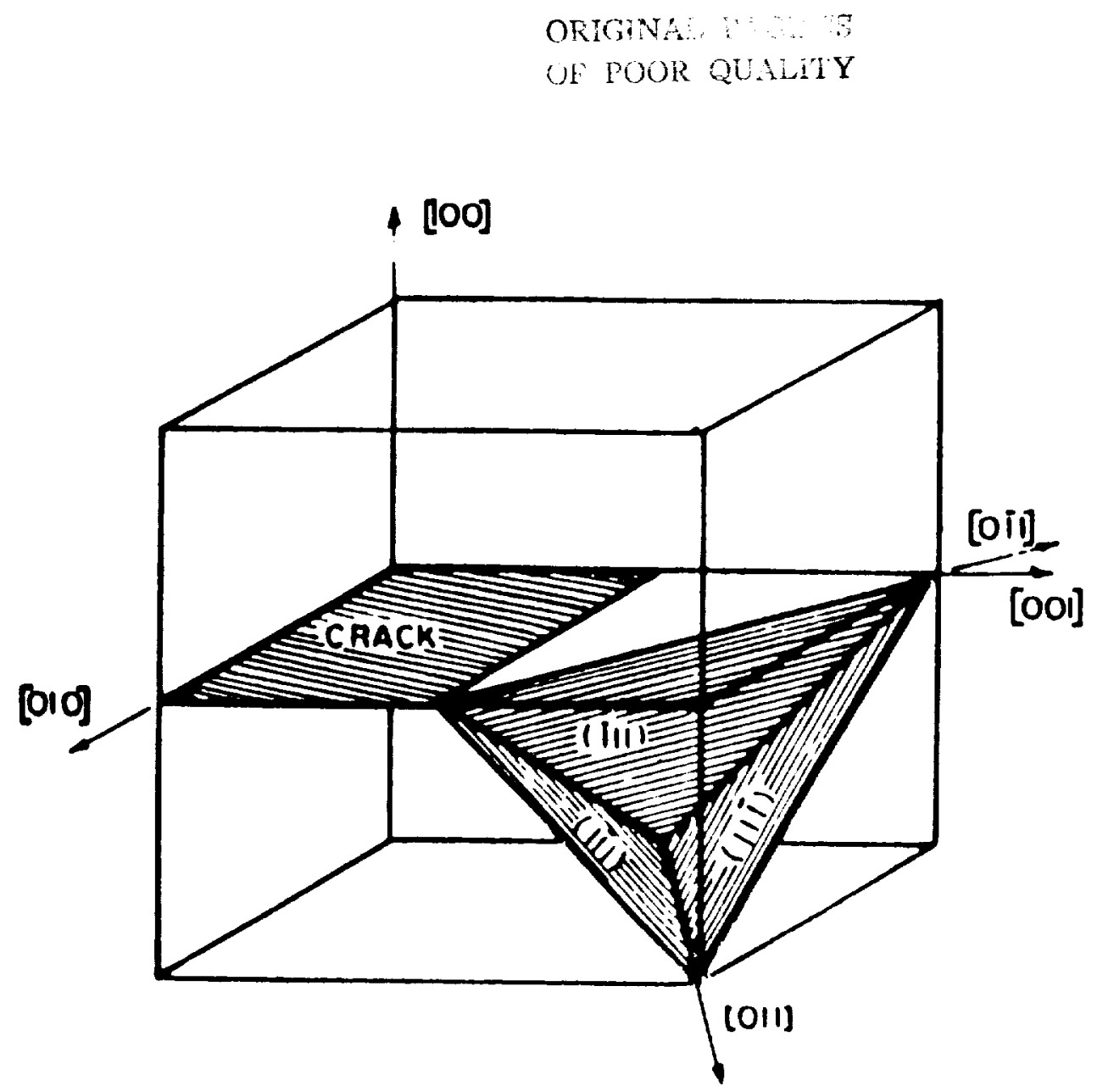

Fig. 12 The orientations of the crack plane and the slip systems. FCC crystal. 


\section{ORIGINAI, PAGE IS}

\section{OF POOP OUALTY}

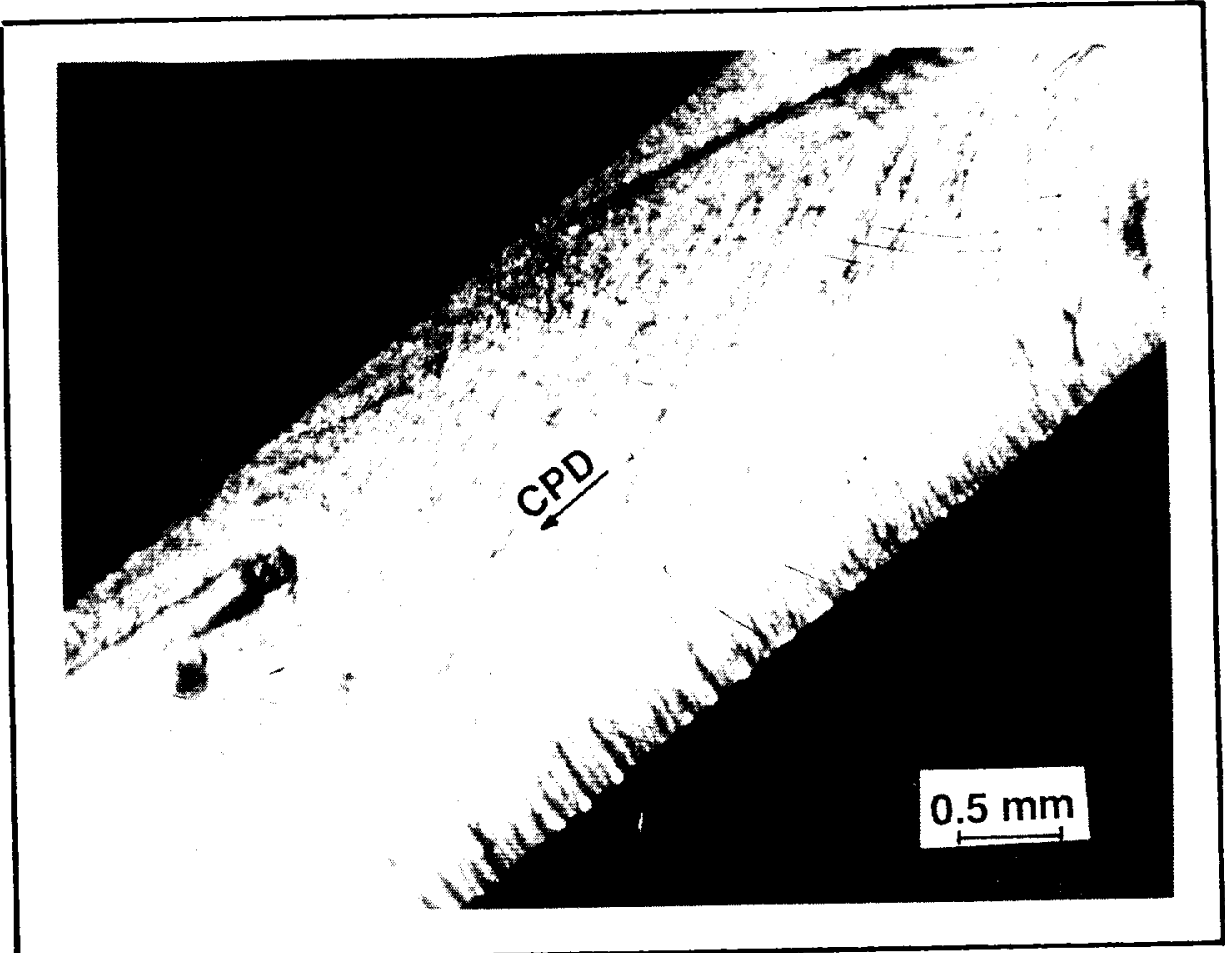

Fig. 13 The optical photograph of the fracture surface of R4.

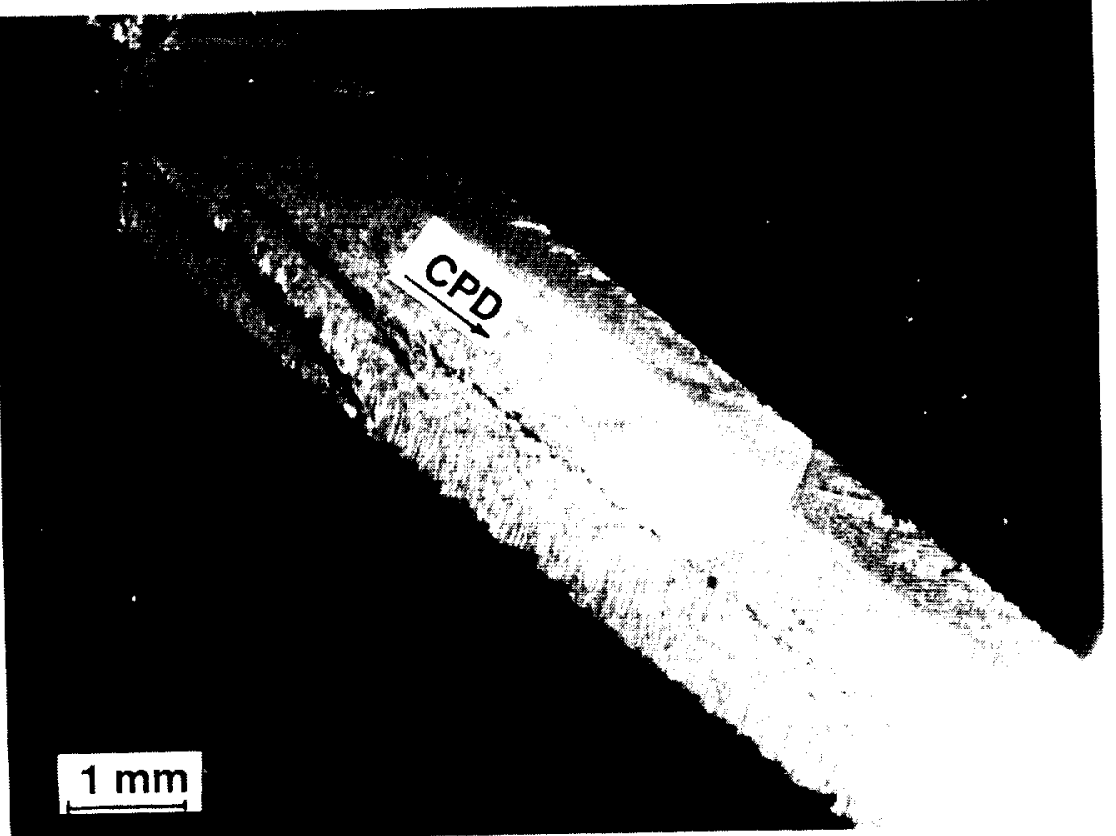

Fig. 14 The optical photograph of the fracture surface of R5. 


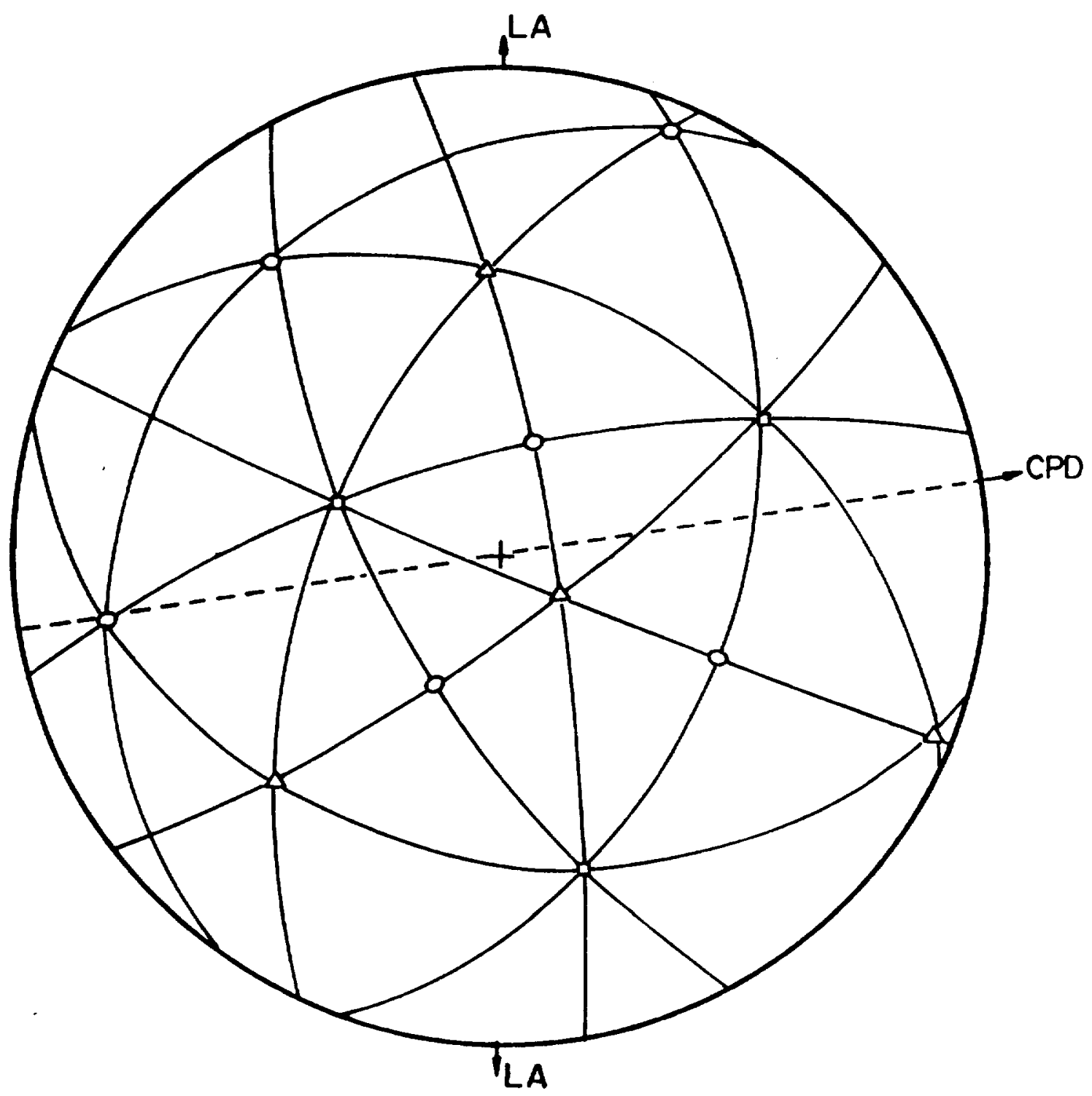

Fig. 15 The stereographic projection of the crystal at the crack tip in Specimen R4. 


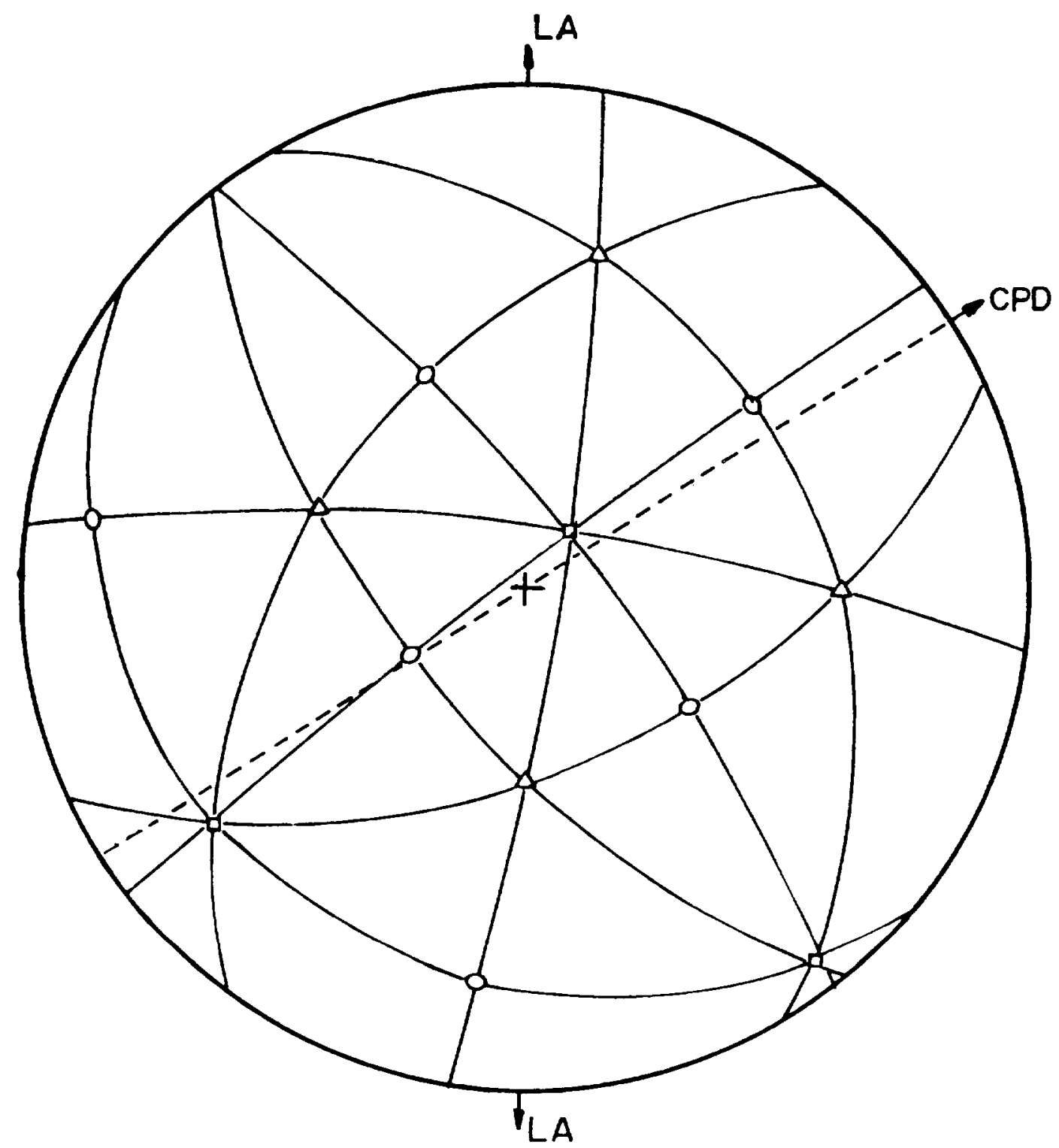

Fig. 16 The stereographic projection of the crystal at the crack tip in Specimen R5. 


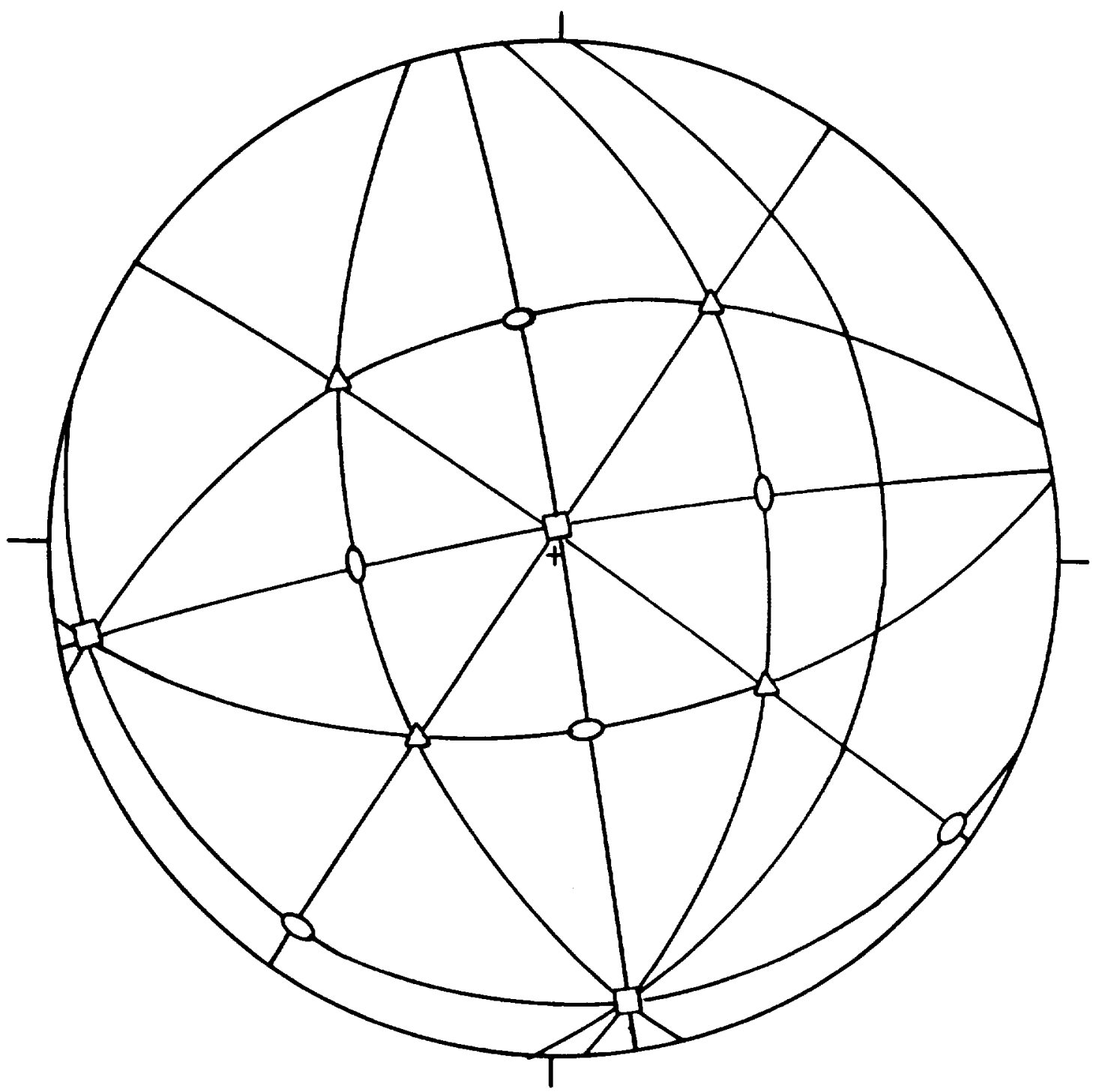

Fig. 17 The stereographic projection of the crack surface of Specimen R5. 


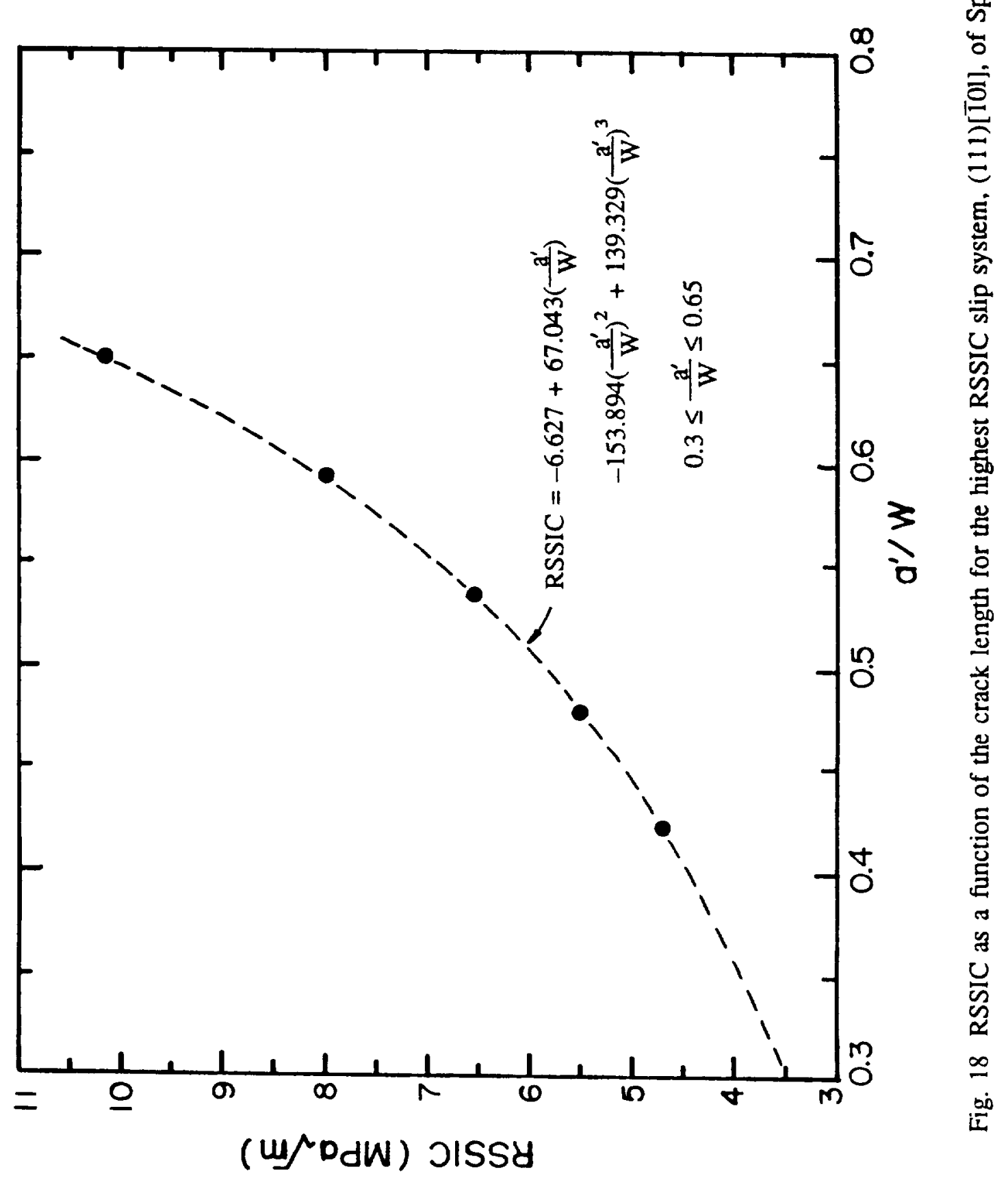




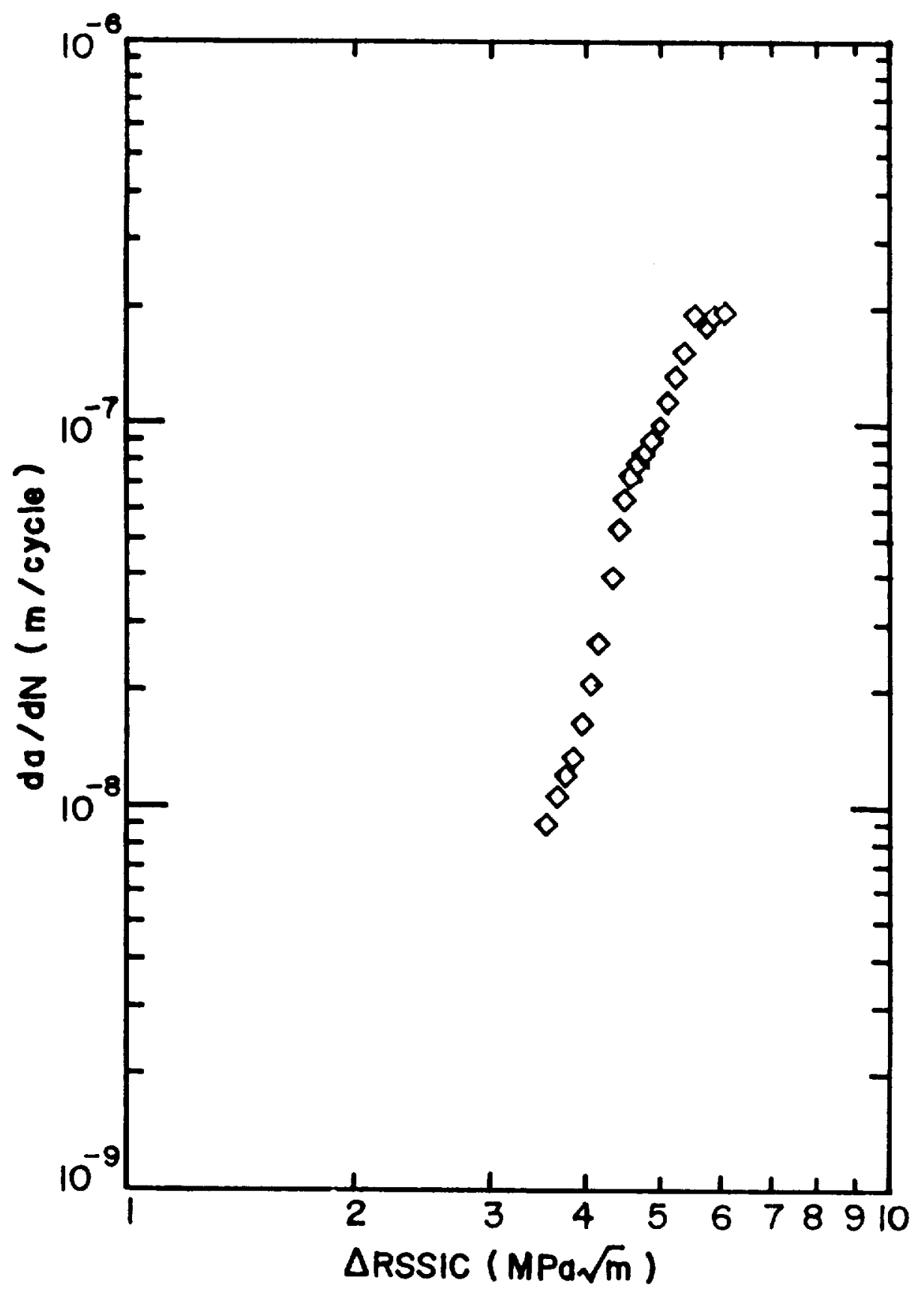

Fig. 19 The fatigue crack growth rate correlation with $\triangle R S S I C$. 



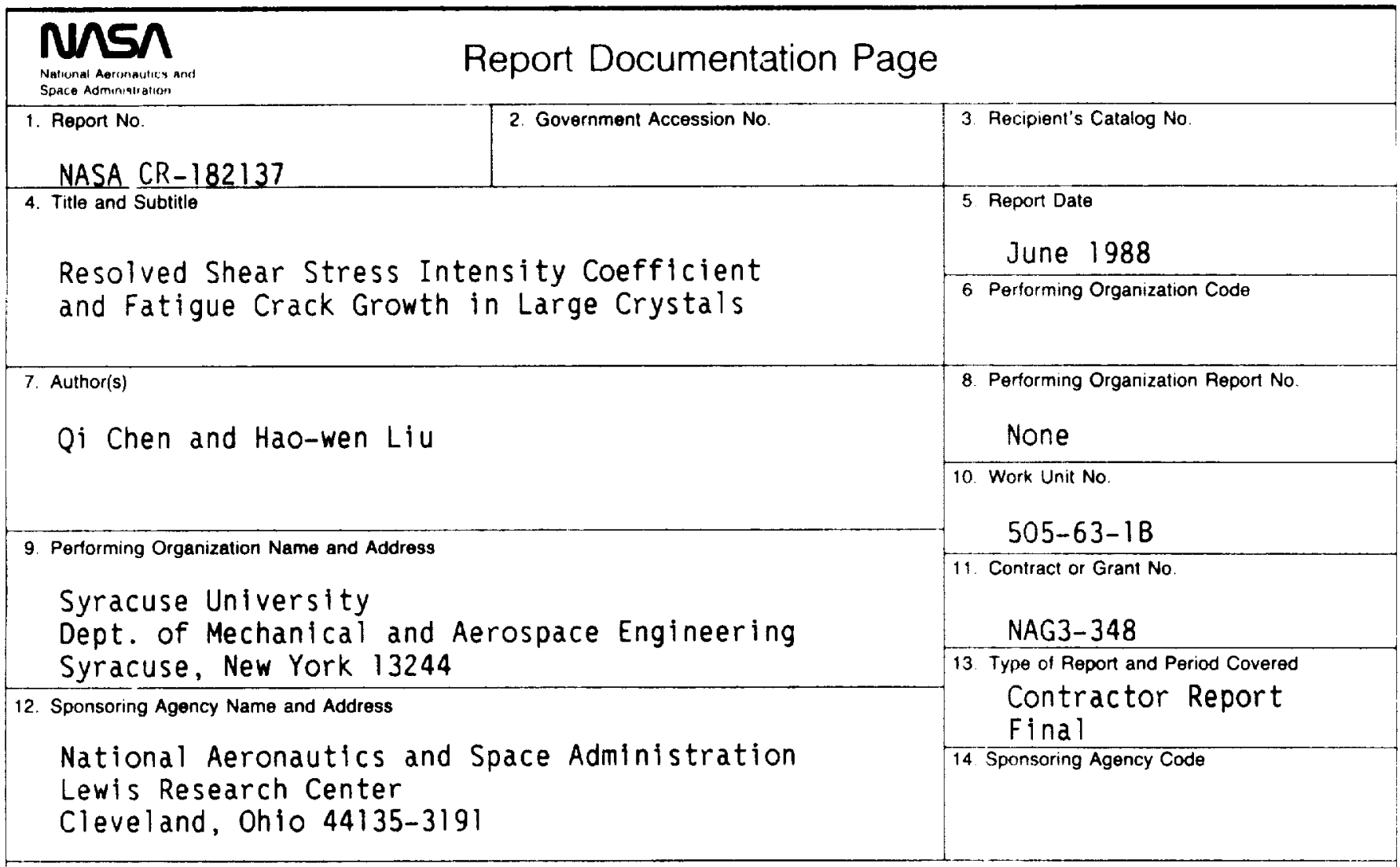

15. Supplementary Notes

Project Manager, Jack Telesman, Structures Division, NASA Lewis Research Center.

16. Abstract

Fatigue crack growth in large grain Al 7029 aluminum alloy was studied. Fatigue crack growth is caused primarily by shear decohesion due to dislocation motion in the crack tip region. The crack paths in the large crystals are very irregular and zigzag. The crack planes are often inclined to the loading axis both in the in-plane direction and the thickness direction. The stress intensity factors, $K_{I}, K_{I I}$, and $K_{I I I}$, of such inclined cracks are approximated from the two-dimensional finite element calculations. The plastic deformation in a large crystal is highly anisotropic, and dislocation motions in such crystals are driven by the resolved shear stress. The resolved shear stress intensity coefficient in a crack solid, RSSIC, is defined, and the coefficierts for the slip systems at a crack tip are evaluated from the calculated stress intensity factors. The orientations of the crack planes are closely related to the slip planes with the high RSSIC values. If a single slip system has a much higher RSSIC than all the others, the crack will follow the slip plane, and the [111] slip plane becomes the crack plane. If two or more slip systems have a high RSSIC, the crack plane is the result of the decohesion processes on these active slip planes. It is suggested that the rate of the crack growth by the mechanism of shear decohesion on a single slip plane should correlate well with the calculated RSSIC of the active slip system. It is expected that the rate of crack growth by shear decohesions on more than one slip system should correlate with a combination of the RSSIC's of the active slip systems.

17. Key Words (Suggested by Author(s))

18. Distribution Statement

Fatigue crack growth; Large grains; Stress intensity coefficient; Single crystals; Resolved shear stress

Unclassified - Unlimited

Subject Category 39

19. Security Classif. (of this report) Unclassified

20. Securlty Classif. (of this page)
Unc las s if ied
Unclassified

\begin{tabular}{|c|r|}
\hline $\begin{array}{c}\text { 21. No of pages } \\
56\end{array}$ & $\begin{array}{r}\text { 22. Price } \\
\text { A04 }\end{array}$ \\
\hline
\end{tabular}

